\title{
What drives the labour wedge? A comparison between CEE countries and the Euro Area
}

\author{
Małgorzata Skibińska \\ Narodowy Bank Polski, ul. Świetokrzyska 11/21, 00-919 Warsaw, Poland \\ Warsaw School of Economics, Al. Niepodlegtości 162, 02-554 Warsaw, Poland
}

\begin{abstract}
We use a structural macroeconomic model with search and matching frictions on the labour market to analyse the differences in the business cycle fluctuations of the labour wedge between two CEE countries and the Euro Area. Our results indicate that the observed higher volatility of this wedge in the CEE region reflects mainly different characteristics of stochastic disturbances rather than country-specific features of the labour market. We also identify significant differences in the sources of labour wedge fluctuations across the considered economies. Overall, we find that the labour wedge movements and hence the welfare costs of business cycle fluctuations in Poland are connected with inefficient functioning of the labour market. To the contrary, wedge fluctuations in the Czech Republic and the
\end{abstract} EA seem to result from the financial frictions.

Keywords: labour wedge, search and matching frictions, business cycle, CEE countries

\section{Introduction}

The standard frictionless real business cycle model assumes that the wage should be equal to the firms' marginal product of labour (MPL) and the households' marginal rate of substitution (MRS). However, the data indicates that this relationship does not hold and that the labour wedge, defined as a gap between these two objects, is characterized by large cyclical variations.

The labour wedge movements drive the fluctuations of other macroeconomic variables. No wonder, then, that a lot of attention in the literature has been devoted to its behaviour. In their influential work, Chari et al. (2007) demonstrated that, along with the efficiency wedge, the labour wedge accounted for most of the variation in U.S. output both during the Great Depression and in the post-war business cycles. Hall (1997) showed that procyclical fluctuations in the gap between the observed components

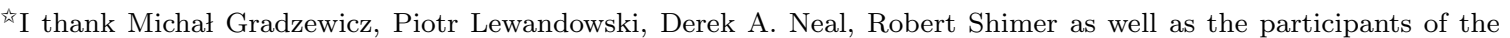
seminar at Barcelona GSE, WIEM conference, Doctoral Workshop on Econometrics and Statistics by University of Lodz and XXX Annual Conference of the Italian Association of Labour Economists. Special thanks to Marcin Kolasa for his support and extremely useful discussions. The views expressed in this paper are those of the author and not necessarily those of Narodowy Bank Polski.

Email address: malgorzta.skibinska@nbp.pl (Małgorzata Skibińska)
} 
of MRS and MPL were crucial for post-war American employment dynamics. Sala et al. (2010) found close correspondence between the output gap and the labour wedge in the U.S. data from the period between 1960 and 2009. Galí et al. (2007) decomposed the labour wedge into price and wage mark-ups and used it to measure the welfare costs of business cycles in the U.S.

More recently, Shimer (2009) and Pescatori and Tasci (2011) showed, using recent U.S. data, that search and matching frictions do not per se help to explain fluctuations in the labour wedge. However, as Shimer (2009) pointed out, subsidiary assumptions in the search models, especially alternative concepts of the wage setting, may help to solve this problem. Karabarbounis (2014) argued that the U.S. labour wedge dynamics reflects predominantly fluctuations in the gap between the real wage and the households' marginal rate of substitution, rather than between the wage and the firms' marginal product of labour. Cheremukhin and Restrepo-Echavarria (2014) used an RBC model with search and matching frictions to decompose the wedge into exogenous separation, bargaining and matching shocks and found that wedge variations in the U.S. are to large extent attributable to changes in the matching efficiency.

The dynamics of the labour wedge differs significantly across countries. For example, it has been empirically proved that the labour wedge in Central and Eastern European countries (CEE) is characterized by higher variability than in the Euro Area (EA) (see, e.g., Kolasa (2013) and Gradzewicz et al. (2012)). Figure 1 presenting the series of the labour wedge in Poland, the Czech Republic and the EA confirms that this wedge in CEE economies is much more volatile. It has been, however, so far unclear what the source of this difference is.

This paper aims to clarify this issue by estimating a small open economy real business cycle model with search and matching frictions on the labour market (see Pissarides (1985) and Mortensen and Pissarides (1994)) for the Eurozone, Poland and the Czech Republic and using it to identify the main driving forces of the labour wedge variations. We choose Poland and the Czech Republic as the representatives of the $\mathrm{CEE}$ region as these economies seem to be respectively the least and the most similar to the Euro Area in terms of the importance of the labour wedge fluctuations for output evolution (see Kolasa (2013)).

The model economy used in our analysis consists of households, two firm sectors, the government and the exogenous foreign economy. The real wage setting mechanism is based on the standard Nash bargaining between the worker and the firm. Additionally, in order to improve model's data fit, our framework includes real wage rigidity and habit persistence in consumption 1 .

\footnotetext{
${ }^{1}$ The labour wedge fluctuations may be affected not only by labour market frictions, but also by other types of market imperfections, in particular product market imperfections. However, estimation of a model with sticky prices and mark-up shocks has demonstrated that the role of such product market frictions for the labour wedge dynamics in the analysed economies is negligible.
} 
Figure 1: Cyclical component of the labor wedge

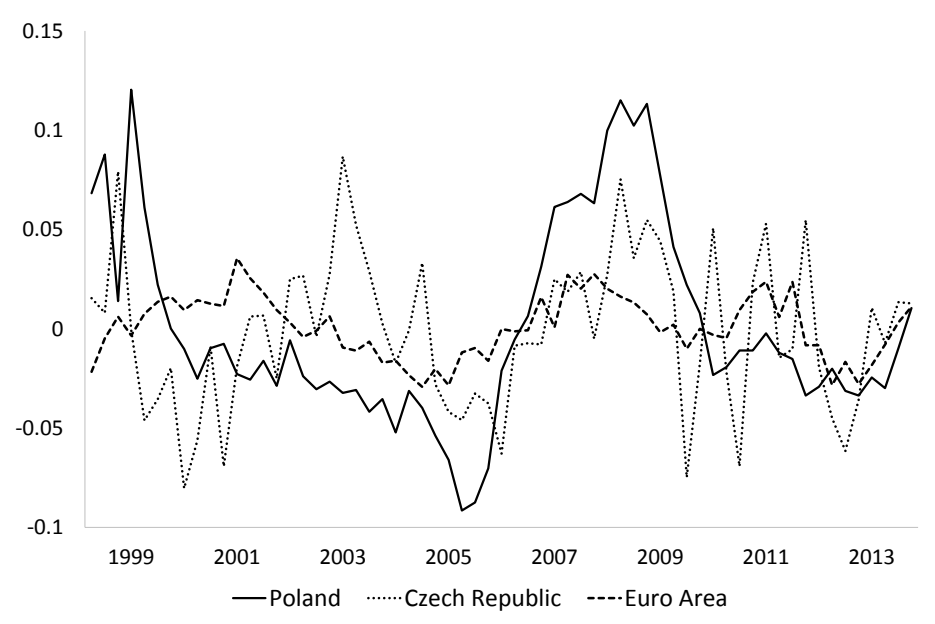

Notes: The labour wedge is calculated according to formula 52 defined in section 2.7 with the parameters set at their posterior means (see section 3.3. The series used are HP-filtered.

The model is estimated with Bayesian methods separately for Poland, the Czech Republic and the Euro Area on seven macroeconomic variables, including real GDP for home and foreign economies, households' and government consumption, unemployment rate, real wages and the number of vacancies. Conformable with the number of variables, the model includes seven structural shocks. The set of stochastic disturbances contains three labour market shocks affecting the job destruction rate, the cost of hiring and workers' bargaining power, as well as four standard shocks used in small open economy frameworks (one supply shock affecting productivity, two demand-side shocks to households' preferences and to government spending, and a shock to foreign output).

First we analyse the variance decomposition of the labour wedge and show that the forces driving its volatility differ across the analysed economies. While the dynamics of the gap between MRS and MPL in Poland can be attributed mainly to labour market disturbances, the consumption preference shock is the main force behind the wedge variability in the Euro Area and the Czech Republic. Borrowing the interpretation of the preference shock from Fisher (2015) and Christiano et al. (2015), we argue that the wedge movements and hence the welfare costs of business cycle fluctuations (Galí et al. 2007) in the Czech Republic and the Euro Area result primarily from financial frictions. By contrast, the wedge fluctuations in the Polish economy seem to be connected with frictional labour market.

In the second step we perform some counterfactual simulations which indicate that the differences in volatilities of the labour wedge in the analysed economies result primarily from the distinct characteristics of stochastic disturbances. However, in Poland the labour market structure also plays some 
role in explaining the differences vis-à-vis the EA. More precisely, lower elasticity of the matching process with respect to unemployment and higher workers' bargaining power contribute to relatively high variability of the wedge in this country. The impact of heterogeneity in these parameters between the EA and the Czech Republic is rather marginal. Moreover, we find that the structural features of the labour market affect the way in which the preference shock propagates through the economy.

Overall, we identify heterogeneity in terms of the labour wedge fluctuations within the CEE region. The Czech Republic stands out as more similar to the EA, not only in the wedge volatility, but also in its driving forces. Poland appears to be structurally different and the welfare costs in this country seem to result from labour market frictions rather than from financial disturbances.

The rest of this paper is organized as follows. The next section lays out the model setup. Section 3 presents the calibration and estimation procedures. Section 4 discusses the results. The last section concludes.

\section{Model economy}

\subsection{Households}

The economy is populated by a number of infinitely-lived households with the continuum of members of measure unity. The fraction of currently employed household members is $N_{t}$, whereas the number of unemployed household members is $U_{t}=1-N_{t}$. The household provides a perfect consumption insurance for its members, implying that consumption is the same for both employed and unemployed workers (Merz 1995). An instantaneous utility is a function of consumption basket $C_{t}$, to be defined below, and the labour effort $N_{t}$. A typical household maximizes the lifetime utility (1) subject to the sequence of the budget constraints 20 and the physical capital accumulation equations (3)

$$
\begin{gathered}
\max _{C_{t}, K_{t+1}, I_{t}, D_{t+1}} E_{0} \sum_{t=0}^{\infty} \beta^{t} \varepsilon_{\beta, t}\left(\frac{\left(C_{t}-h \tilde{C}_{t-1}\right)^{1-\zeta}}{1-\zeta}-\kappa^{L} \frac{N_{t}^{1+\phi}}{1+\phi}\right) \\
P_{t} C_{t}+P_{t}^{I} I_{t}+T_{t}+E_{t}\left[Q_{t, t+1} D_{t+1}\right]=P_{t} b U_{t}+W_{t} N_{t}+R_{t} K_{t}+\Pi_{t}+D_{t} \\
K_{t+1}=K_{t}(1-\delta)+I_{t}
\end{gathered}
$$

where $E_{t}$ denotes the expectation operator taken at time t, $\beta$ is the discount factor, $h$ is the external habit motive, $\tilde{C}_{t}$ denotes the average consumption, $\kappa^{L}$ is the parameter scaling the disutility of work, $\zeta$ is the inverse of intertemporal substitution elasticity, $\phi$ stands for the inverse of the Frisch elasticity of labour supply, $P_{t}$ is the price for the consumption bundle $C_{t}, P_{t}^{I}$ denotes the price for the investment bundle $I_{t}, T_{t}$ stands for the nominal government taxes, $D_{t}$ is the portfolio of Arrow-Debreu securities, 
$Q_{t, t+1}$ is the stochastic discount factor, $b$ refers to the real unemployment benefits, $R_{t}$ is the nominal rental rate of capital $K_{t}, \delta$ is the depreciation rate, and $\varepsilon_{\beta, t}$ denotes the preference shock that obeys

$$
\ln \left(\varepsilon_{\beta, t}\right)=\rho_{\beta} \ln \left(\varepsilon_{\beta, t-1}\right)+\epsilon_{\beta, t}
$$

and where all innovations, including $\epsilon_{\beta, t}$ are zero-mean i.i.d. random variables.

The consumption bundle $C_{t}$ consists of home-made goods $C_{H, t}$ and foreign-made goods $C_{F, t}$ aggregated according to

$$
C_{t}=\left(\alpha^{\prime \frac{1}{\omega^{\prime}}}\left(C_{H, t}\right)^{\frac{\omega^{\prime}-1}{\omega^{\prime}}}+\left(1-\alpha^{\prime}\right)\left(C_{F, t}\right)^{\frac{\omega^{\prime}-1}{\omega^{\prime}}}\right)^{\frac{\omega^{\prime}}{\omega^{\prime}-1}}
$$

The optimal allocation of the expenditures between the domestic and imported goods is given by

$$
C_{H, t}=\alpha^{\prime}\left(\frac{P_{t}}{P_{H, t}}\right)^{-\omega^{\prime}} C_{t} \quad C_{F, t}=\left(1-\alpha^{\prime}\right)\left(\frac{P_{t}}{P_{F, t}}\right)^{-\omega^{\prime}} C_{t}
$$

where $P_{H, t}$ denotes the price of domestic goods, $P_{F, t}$ stands for the price of imported goods and the aggregate price $P_{t}$ is given by

$$
P_{t}=\left(\alpha^{\prime}\left(P_{H, t}\right)^{1-\omega^{\prime}}+\left(1-\alpha^{\prime}\right)\left(P_{F, t}\right)^{1-\omega^{\prime}}\right)^{\frac{1}{1-\omega^{\prime}}}
$$

The investment bundle $I_{t}$ is aggregated in the similar fashion as the consumption good, which implies the following definitions

$$
\begin{gathered}
I_{t}=\left(\alpha^{\prime \prime \frac{1}{\omega^{\prime \prime}}}\left(I_{H, t}\right)^{\frac{\omega^{\prime \prime}-1}{\omega^{\prime \prime}}}+\left(1-\alpha^{\prime \prime}\right)\left(I_{F, t}\right)^{\frac{\omega^{\prime \prime}-1}{\omega^{\prime \prime}}}\right)^{\frac{\omega^{\prime \prime}}{\omega^{\prime \prime}-1}} \\
I_{H, t}=\alpha^{\prime}\left(\frac{P_{t}^{I}}{P_{H, t}}\right)^{-\omega^{\prime \prime}} I_{t} \quad I_{F, t}=\left(1-\alpha^{\prime \prime}\right)\left(\frac{P_{t}^{I}}{P_{F, t}}\right)^{-\omega^{\prime \prime}} I_{t} \\
P_{t}^{I}=\left(\alpha^{\prime \prime}\left(P_{H, t}\right)^{1-\omega^{\prime \prime}}+\left(1-\alpha^{\prime \prime}\right)\left(P_{F, t}\right)^{1-\omega^{\prime \prime}}\right)^{\frac{1}{1-\omega^{\prime \prime}}}
\end{gathered}
$$

\subsection{Labour market}

Household members are employed by intermediate firms indexed by $i$ on the unit interval. In order to attract and employ new workers, the intermediate producers need to post vacancies. The matching process which describes how the vacancies and the unemployed workers get together is given by the standard Cobb-Douglas matching technology

$$
M_{t}=\sigma^{m} U_{t}^{\sigma} V_{t}^{1-\sigma}
$$

where $M_{t}$ is the number of new matches, $\sigma^{m}$ is the parameter describing the matching efficiency and $V_{t}$ is the number of vacant jobs. The aggregate labour market tightness is defined as

$$
\theta_{t}=\frac{V_{t}}{U_{t}}
$$


An average probability that a searching worker finds a job is given by

$$
s_{t}=\frac{M_{t}}{U_{t}}=\sigma^{m} \theta_{t}^{1-\sigma}
$$

Similarly, an average probability that the firm fills the vacancy is given by

$$
q_{t}=\frac{M_{t}}{V_{t}}=\sigma^{m} \theta_{t}^{-\sigma}
$$

Each period the exogenous fraction $\varrho_{t}$ of employed workers is separated from their jobs. Additionally, the total workforce is enlarged by the flows from unemployment to employment from the previous period (Gertler and Trigari 2009, Moyen and Sahuc 2005). The employment law of motion is thus given by

$$
N_{t}=\left(1-\varrho_{t}\right) N_{t-1}+M_{t-1}
$$

where $\varrho_{t}$ is assumed to follow $\mathrm{AR}(1)$ process

$$
\ln \left(\varrho_{t}\right)=\left(1-\rho_{\varrho}\right) \ln (\varrho)+\rho_{\varrho} \ln \left(\varrho_{t-1}\right)+\epsilon_{\varrho, t}
$$

and where $\varrho$ represents the steady state job destruction rate.

\subsection{Firms}

In our economy there are two sectors of production. Firms in the first sector produce the differentiated goods using the labour and capital rented from households. The firms in the second sector aggregate the differentiated intermediate goods into a homogeneous final good $Y_{t}$ and sell it at price $P_{H, t}$.

\subsubsection{Final good producers}

The final good producers operate in the perfectly competitive environment. They take the differentiated intermediate goods indexed by $i$ on the unit interval and bundle them according to Dixit-Stiglitz technology (18). In order to maximize their profits, they solve the following problem

$$
\max _{Y_{t}(i), Y_{t}} P_{H, t} Y_{t}-\int_{0}^{1} P_{H, t}(i) Y_{t}(i) d i
$$

subject to

$$
Y_{t}=\left(\int_{0}^{1} Y_{t}(i)^{\frac{1}{\mu}} d i\right)^{\mu}
$$

where $\mu$ denotes the intermediate producers' gross price mark-up.

The price level satisfying the zero-profit condition is defined by

$$
P_{H, t}=\left(\int_{0}^{1} P_{H, t}(i)^{\frac{1}{1-\mu}} d i\right)^{1-\mu}
$$




\subsubsection{Intermediate goods producers}

Intermediate firms use the capital and labour as the input in their production process. They also have to pay the real cost $\kappa_{t}^{v}$ for posting vacant jobs. Their aim is to maximize profits 20] facing the demand of the final producers 21, constant return to scale Cobb-Douglas production technology 22. and the law of motion for employment 23 ]

$$
\max _{\substack{Y_{t}(i), K_{t}(i), N_{t}(i), P_{H, t}(i), V_{t}(i)}} E_{0} \sum_{t=0}^{\infty} \beta_{0, t}\left[P_{H, t}(i) Y_{t}(i)-W_{t}(i) N_{t}(i)-P_{H, t} \kappa_{t}^{v} V_{t}(i)-R_{t} K_{t}(i)\right]
$$

subject to

$$
\begin{gathered}
Y_{t}(i)=\left(\frac{P_{H, t}(i)}{P_{H, t}}\right)^{-\frac{\mu}{\mu-1}} Y_{t} \\
Y_{t}(i)=Z_{t} K_{t}(i)^{\alpha} N_{t}(i)^{1-\alpha} \\
N_{t}(i)=\left(1-\varrho_{t}\right) N_{t-1}(i)+q_{t-1} V_{t-1}(i)
\end{gathered}
$$

where $\beta_{0, t}$ is the equilibrium stochastic discount factor consistent with households' preferences and is given by

$$
\beta_{t, t+s}=\beta^{s} E_{t}\left[\frac{\lambda_{t+s}}{\lambda_{t}}\right]=\beta^{s} E_{t}\left[\frac{\epsilon_{\beta, t+s} u_{C}\left(C_{t+s}, N_{t+s}\right)}{\epsilon_{\beta, t} u_{C}\left(C_{t}, N_{t}\right)}\right]
$$

and where the productivity $Z_{t}$ and the real hiring cost $\kappa_{t}^{v}$ are given by exogenous $\mathrm{AR}(1)$ processes

$$
\begin{gathered}
\ln \left(Z_{t}\right)=\rho_{z} \ln \left(Z_{t-1}\right)+\epsilon_{z, t} \\
\ln \left(\kappa_{t}^{v}\right)=\left(1-\rho_{v}\right) \ln \left(\kappa^{v}\right)+\rho_{v} \ln \left(\kappa_{t-1}^{v}\right)+\epsilon_{v, t}
\end{gathered}
$$

\subsubsection{Wage setting}

Forming the match entails economic rents which have to be shared between two parties of the matching process i.e. a worker and a firm. We assume that the way in which the overall surplus from the match is divided is determined in the standard generalized Nash bargaining. Taking into account that problems of all agents in the model are symmetric, we can omit the $i$ indices in all the equations below.

The value for the household of having employed worker earning the real wage $w_{t}$ is given by the combination of the wage income, the utility loss from working and the continuation value. With probability $1-\varrho_{t+1}$ the worker will stay employed for the next period and with probability $\varrho_{t+1}$ he will lose his job. The value of the worker when employed is thus given by

$$
\mathcal{V}_{t}^{W}=w_{t}-\kappa^{L} \frac{N_{t}^{\phi}}{\left(C_{t}-h \tilde{C}_{t-1}\right)^{-\zeta}}+E_{t} \beta_{t, t+1}\left[\left(1-\varrho_{t+1}\right) \mathcal{V}_{t+1}^{W}+\varrho_{t+1} \mathcal{V}_{t+1}^{U}\right]
$$


The value of the unemployed worker is defined by

$$
\mathcal{V}_{t}^{U}=b+E_{t} \beta_{t, t+1}\left[s_{t} \mathcal{V}_{t+1}^{W}+\left(1-s_{t}\right) \mathcal{V}_{t+1}^{U}\right]
$$

In the current period, an unemployed receives an unemployment benefit $b$ and has a chance equal to $s_{t}$ of finding a job in the next period. With probability equal to $1-s_{t}$, the worker stays unemployed.

The household's surplus from having employed rather than unemployed member is given by

$$
S_{t}^{W}=w_{t}-\kappa^{L} \frac{N_{t}^{\phi}}{\left(C_{t}-h \tilde{C}_{t-1}\right)^{-\zeta}}-b+E_{t} \beta_{t, t+1}\left(1-\varrho_{t+1}-s_{t}\right) S_{t}^{W}
$$

The firm's value of the job matched to the worker who receives the real wage $w_{t}$ is given by

$$
\mathcal{V}_{t}^{J}=m c_{t} f_{N, t}-w_{t}+E_{t} \beta_{t, t+1}\left[\left(1-\varrho_{t+1}\right) \mathcal{V}_{t+1}^{J}+\varrho_{t+1} \mathcal{V}_{t+1}^{V}\right]
$$

Here $m c_{t}$ denotes the real marginal cost of the $i$-th intermediate producer, which, multiplied by the marginal product of labour $f_{N, t}$ gives the workers contribution to the firm's profits. In the next period, with probability $1-\varrho_{t+1}$ the job will be still matched with the worker and with probability $\varrho_{t+1}$ the match will be separated. The value of an open vacancy for the firm is given by

$$
\mathcal{V}_{t}^{V}=-\frac{P_{H, t}}{P_{t}} \kappa_{t}^{v}+E_{t} \beta_{t, t+1}\left[q_{t} \mathcal{V}_{t+1}^{J}+\left(1-q_{t}\right) \mathcal{V}_{t+1}^{V}\right]
$$

Due to the free entry into vacancy posting, having vacant jobs by the firm is economically worthless, i.e. $\mathcal{V}_{t}^{V}=0$ at any time t. Thus, the total firm's surplus from the match is given by

$$
S_{t}^{F}=m c_{t} f_{N, t}-w_{t}+E_{t} \beta_{t, t+1}\left(1-\varrho_{t+1}\right) S_{t+1}^{F}
$$

The negotiated wage depends on the relative bargaining strength of both match participants and satisfies

$$
w_{t}^{N}=\operatorname{argmax}\left(S_{t}^{W}\right)^{\eta_{t}}\left(S_{t}^{F}\right)^{1-\eta_{t}}
$$

The workers' bargaining power $\eta_{t}$ is assumed to evolve according to

$$
\ln \left(\eta_{t}\right)=\left(1-\rho_{\eta}\right) \ln (\eta)+\rho_{\eta} \ln \left(\eta_{t-1}\right)+\epsilon_{\eta, t}
$$

where $\eta$ is the steady state workers' bargaining power. Solving the problem above and using the definitions of firm's and worker's surpluses gives the equation for the negotiated wage level $w_{t}^{N}$

$$
w_{t}^{N}=\left(1-\eta_{t}\right)\left[b+\kappa^{L} \frac{N_{t}^{\phi}}{\left(C_{t}-h \tilde{C}_{t-1}\right)^{-\zeta}}\right]+\eta_{t}\left[m c_{t} f_{N, t}+\frac{P_{H, t}}{P_{t}} \kappa_{t}^{v} \theta_{t}\right]
$$

It is empirically proved that the models with fully flexible wages fail in reflecting the dynamics of the labour market variables (Blanchard and Galí 2010, Shimer 2005). As a result, many forms of wage rigidities were proposed in the literature. In our model we use the adaptive wage introduced by Hall 
(2005), according to which the current level of wage is set as the weighted average of the wage from the previous period and the Nash bargaining solution. Thus, the average real wage level is given by

$$
w_{t}=\alpha_{w} w_{t}^{N}+\left(1-\alpha_{w}\right) w_{t-1}
$$

where $1-\alpha_{w}$ describes the degree of wage rigidity.

\subsection{Government}

The government levies lump-sum taxes $T_{t}$ on households and spends them on government consumption $g_{t}$ and unemployment benefits $b$. We assume that the government consumes only domestic goods implying that the price of government consumption is $P_{H, t}$. The government budget constraint satisfies

$$
P_{H, t} g_{t}+P_{t} b U_{t}=T_{t}
$$

where government consumption $g_{t}$ is given by exogenous $\mathrm{AR}(1)$ process

$$
\ln \left(g_{t}\right)=\left(1-\rho_{g}\right) \ln (g)+\rho_{g} \ln \left(g_{t-1}\right)+\epsilon_{g, t}
$$

and where $g$ is the steady state level of government spending.

\subsection{Foreign economy, exchange rate and exports}

We assume that the domestic economy is "small" compared to the foreign one. Thus, anything that happens abroad is completely unaffected by what happens in the domestic economy. Therefore, foreign output is exogenous and follows the $\operatorname{AR}(1)$ process

$$
\ln \left(\frac{Y_{t}^{*}}{Y^{*}}\right)=\rho_{y} \ln \left(\frac{Y_{t-1}^{*}}{Y^{*}}\right)+\epsilon_{y, t}
$$

where $Y^{*}$ is the steady state value of foreign GDP.

Moreover, we assume that the law of one price holds at all times, which, given that the problems of all agents are symmetric and all firms choose the same price, implies that

$$
P_{F, t}=e_{t} P_{t}^{*}
$$

where $e_{t}$ is the nominal exchange rate and $P_{t}^{*}$ denotes foreign goods price measured in foreign currency. Following Galí and Monacelli (2005), we also define the bilateral real exchange rate $Q_{t}$ as the ratio of foreign and domestic Consumer Price Indices, both measured in domestic currency

$$
Q_{t}=\frac{e_{t} P_{t}^{*}}{P_{t}}
$$

Since international markets are complete, the real exchange rate can also be expressed as follows (Chari et al. 2002)

$$
\frac{\lambda_{t}^{*}}{\lambda_{t}}=\frac{1}{\varepsilon_{\beta, t}}\left(\frac{C_{t}^{*}-h \tilde{C}_{t-1}^{*}}{C_{t}-h \tilde{C}_{t-1}}\right)^{-\zeta}=Q_{t}
$$


where $C_{t}^{*}$ is foreign consumption.

In the equation above we assume that the world economy is characterized by the same households' preferences as the domestic one and there are no preference shocks abroad.

Finally, we define the total demand for domestically produced goods by foreigners as (Christiano et al. 2011)

$$
X_{t}=\psi\left(\frac{P_{H, t}}{e_{t} P_{t}^{*}}\right)^{-\omega} Y_{t}^{*}
$$

where $X_{t}$ denotes exports, $\psi$ is the exports scaling parameter and $\omega$ represents the relative price elasticity of demand for exports.

\subsection{Market clearing}

Several market clearing conditions must hold in the equilibrium. Firstly, the total demand for capital by all intermediate producers has to be equal to its supply offered by households

$$
K_{t}=\int_{0}^{1} K_{t}(i) d i
$$

Similarly, the aggregate numbers of employed workers and vacancies have to satisfy

$$
\begin{aligned}
& N_{t}=\int_{0}^{1} N_{t}(i) d i \\
& V_{t}=\int_{0}^{1} V_{t}(i) d i
\end{aligned}
$$

Moreover, net foreign assets in the equilibrium are given by

$$
E_{t}\left[Q_{t, t+1} D_{t+1}\right]=D_{t}+N X_{t}
$$

where $N X_{t}$ denotes net exports and is defined by

$$
N X_{t}=P_{H, t} X_{t}-P_{F, t}\left(C_{F, t}+I_{F, t}\right)
$$

Using the equations above and combining the budget constraints of all agents of the model yields the standard resource constraint in the final goods market, which is given by

$$
Y_{t}=C_{H, t}+I_{H, t}+g_{t}+\kappa_{t}^{v} V_{t}+X_{t}
$$

Finally, we have to ensure that the market of final foreign goods clears. Assuming that there is no distinction between the investment and consumption goods abroad, the world market clearing condition can be stated as follows

$$
C_{t}^{*}=Y_{t}^{*}
$$




\subsection{Labour wedge}

Following Chari et al. (2007), we define the labour wedge as a difference between households' (log) marginal rate of substitution and firm's (log) marginal product of labour

$$
\text { wedge }_{t}=m r s_{t}-m p l_{t}
$$

Using the functional forms of the production technology and the utility function, we get that the labour wedge is, up to an additive constant, given by the following formula

$$
\text { wedge }_{t}=\left(\phi \hat{N}_{t}+\zeta \frac{\hat{C}_{t}-h \hat{C}_{t-1}}{1-h}\right)-\left(\hat{Y}_{t}-\hat{N}_{t}\right)
$$

where the variables with hats denote the log deviations from the deterministic steady state.

\section{Calibration and estimation}

\subsection{Data}

We estimate the log-linearized version of the model separately for Poland, the Czech Republic and the Eurozone (comprising 18 member countries). Consistently with the number of structural shocks in the model, for the estimation we employ seven observable macroeconomic variables: output (measured as real GDP), consumption (measured as the final consumption expenditure of households for the CEE countries and, due to the lack of relevant data, as the final consumption expenditure of households and non-profit institutions serving households for the $\mathrm{EA}^{2} \mathrm{I}^{3}$, government consumption (the final consumption expenditure of general government), unemployment (the unemployment rate), vacancies (total unfilled job vacancies), wages (real wage per employee in Poland and in the Eurozone and real compensation per employee in the Czech Republic) and foreign output (real GDP of the EA (18 countries) in the model for the CEE economies and real GDP of the U.S. in the model for the EA).

Most of the time series are taken from the Eurostat. However, due to the lack of several variables in this database, we also use other data sources. Thus, the time series of wage per employee in Poland comes from the Polish Central Statistical Office (GUS). The data on wage per employee and the unemployment rate in the EA is taken from the Area-Wide-Model database. The measure of vacancies for all three considered economies is taken from the OECD statistics. As the number of

\footnotetext{
${ }^{2}$ Due to the lack of the quarterly data on individual government consumption, it is impossible to incorporate it into the measures of households' consumption. However, the analysis of the annual time series of these variables suggests that the mismeasurement of the MRS resulting from omitting this consumption component is not big.

${ }^{3}$ Using the time series of final consumption expenditure of households and non-profit institutions serving households as a measure of consumption for all considered economies does not change the main findings of the paper.
} 
vacancies in the EA is not readily available, we construct the measure of vacancies by calculating the population-weighted average from the individual data from six EA member countries 4

The sample starts from 1997q1 and ends in 2013q4, except for the Czech time series that are available from 1998q1. All data used in the estimation of the model is expressed in quarterly frequency, seasonally adjusted and expressed in constant prices from the year 2005. Since in the theoretical model the size of the labour force is normalized to unity, all variables used in estimation are expressed in per labour force terms. As the model is stationary, we detrend the logs of all data using the HodrickPrescott filter $(\lambda=1600)$.

In order to fit the model to the data, we apply the mixture of calibration and estimation. First, we calibrate the important steady state ratios and the parameters for which there is not enough information in the data. Then, we perform the Bayesian estimation for the rest of the parameters.

\subsection{Calibration}

Table 1 presents the important calibrated parameters and steady state ratios. Most of the parameters are consistent with the standard DSGE models (see, e.g., Gomes et al. (2012), Smets and Wouters (2003) and Stähler and Thomas (2012)).

The steady state government spending $g$ is calibrated in order to satisfy the government spending to output ratios of 0.177 for the Polish economy, 0.211 for the Czech Republic and 0.207 for the EA. The output elasticity for capital $\alpha$ is set to meet investment to output ratios equal to 0.205 for Poland, 0.260 for the Czech Republic and 0.201 for the EA. The scaling parameter in the households' utility function $\kappa^{L}$ targets the steady state unemployment rates of 0.132 for Poland, 0.072 for the Czech Republic and 0.095 for the Eurozone. All the above steady state ratios are computed as the averages over the collected data sample.

\footnotetext{
${ }^{4}$ For constructing the EA vacancy index we use data from Austria, Finland, Germany, Luxembourg, Portugal and Holland. Data from the entire analysed sample for the rest of EA member is not available.
} 
Table 1: Important calibrated parameters and steady state ratios

\begin{tabular}{llll}
\hline Parameter/steady state ratio & Value & & \\
\hline$\beta$ & PL & CZ & EA \\
$\delta$ & 0.990 & 0.990 & 0.990 \\
$\mu$ & 0.025 & 0.025 & 0.025 \\
$\alpha$ & 1.100 & 1.100 & 1.100 \\
$\alpha^{\prime}$ & 0.316 & 0.401 & 0.310 \\
$\alpha^{\prime \prime}$ & 0.751 & 0.614 & 0.859 \\
$\kappa^{L}$ & 0.521 & 0.479 & 0.608 \\
$\varrho$ & 1.150 & 0.864 & 1.355 \\
$\sigma^{m}$ & 0.029 & 0.028 & 0.035 \\
$\frac{\kappa^{v} V}{Y}$ & 0.346 & 0.456 & 0.414 \\
$\frac{b}{w}$ & 0.005 & 0.005 & 0.005 \\
$\frac{g}{Y}$ & 0.480 & 0.565 & 0.557 \\
\hline
\end{tabular}

The import content of households' consumption $1-\alpha^{\prime}$ and the import content of total investment $1-\alpha^{\prime \prime}$ are set to respectively 0.249 and 0.479 for Poland, 0.386 and 0.521 for the Czech Republic (Bussière et al. 2013) and 0.141 and 0.393 for the Eurozone (Brzoza-Brzezina et al. 2014). The steady state job destruction rate $\varrho$ is calibrated to 0.029 for Poland and to 0.028 for the Czech Republic (Hobijn and Şahin 2009). The steady state separation rate in the EA is set to 0.035 which is the population-weighted average of separation rates from eleven EA member states documented by Hobijn and Şahin (2009)

Similarly, the steady state replacement rate $\frac{b}{w}$ in the EA is set as the population-weighted average over the replacement rates from seventeen EA member states (except Cyprus) available in the OECD's Benefits and Wages statistics. In order to calculate the replacement rates for the individual countries, we use data from 2012, which is the last vintage available, and take the simple average over the replacement rates for the initial phase of unemployment and long-term unemployment, different family types and earnings levels 6 The replacement rate computed in such way is equal to 0.480 for Poland, 0.565 for the Czech Republic and 0.557 for the EA.

\footnotetext{
5 Hobijn and Şahin (2009) documented the job destruction rates for the following EA members: Belgium, Finland. France, Germany, Greece, Ireland, Italy, Luxembourg, Holland, Portugal and Spain.

${ }^{6}$ The OECD reports net replacement rates for six family categories: single person, one-earner married couple, twoearner married couple, lone parent with 2 children, one-earner married couple with 2 children and two-earner married couple with 2 children. We consider the replacement rates when the pre-unemployment income is $67 \%$ and $100 \%$ of the income of an average production worker.
} 
The discount factor $\beta$ in all three economies is set to 0.99 , which is common in the models estimated on quarterly data. The capital depreciation rate $\delta$ is set at 0.025 , in line with the DSGE literature. The gross price mark-up $\mu$ is calibrated to the standard value of 1.1. Lacking any direct evidence about the steady state vacancy filling probabilities $q$, we set the efficiency of the matching process $\sigma^{m}$ in order to meet $q=0.7$. This value is commonly used in the models for the U.S. (Trigari 2006) and the EA (Christoffel et al. 2009). The real vacancy posing cost $\kappa^{v}$ is calibrated to meet the steady state hiring costs to output ratio of $0.5 \%$, which is somewhere in between the values used in the search literature (see Blanchard and Galí (2010) and Christoffel et al. (2009)).

\subsection{Estimation results}

For estimation purposes, we employ the Bayesian approach. The posterior distribution is explored by generating draws with the use of Markov-Chain Monte-Carlo algorithm, Metropolis-Hastings implementation. In order to estimate the model, we use the Dynare package. We use the Metropolis-Hastings algorithm with 700000 draws in two independent chains (first 350000 draws are dropped) and an acceptance rate equal to about $24 \%$. The convergence of Markov Chains is evaluated using the Brooks and Gelman diagnostics charts (1998).

The choice of prior distributions for the estimated parameters is based mainly on Smets and Wouters (2003), Christoffel et al. (2009), Adolfson et al. (2007) and, to some extent, preliminary experimentation with the model. Generally, the prior distributions for structural parameters and shock properties do not differ across the three economies. The only exceptions here are autoregressive coefficients in the government spending and the foreign output equations which are determined on the basis of the estimation of $\mathrm{AR}(1)$ processes outside the model. The prior distributions together with the estimation results are reported in Table 2 (structural parameters), Table 3 (shocks' persistence) and Table 4 (shocks' standard deviations). The graphical representation of the estimation results is presented in the Appendix. 
Table 2: Estimation results - structural parameters

\begin{tabular}{|c|c|c|c|c|c|c|}
\hline & \multicolumn{3}{|c|}{ Prior distribution } & \multicolumn{3}{|c|}{ Posterior distribution } \\
\hline & Type & Mean & $\mathrm{SD}$ & $5 \%$ & Mean & $95 \%$ \\
\hline \multicolumn{7}{|c|}{ Poland } \\
\hline$\zeta$ & gamma & 2.00 & 0.25 & 1.327 & 1.668 & 1.988 \\
\hline$\phi$ & gamma & 2.00 & 0.25 & 1.516 & 1.924 & 2.311 \\
\hline$h$ & beta & 0.70 & 0.10 & 0.273 & 0.391 & 0.512 \\
\hline$\sigma$ & beta & 0.60 & 0.10 & 0.441 & 0.549 & 0.657 \\
\hline$\eta$ & beta & 0.50 & 0.10 & 0.493 & 0.620 & 0.745 \\
\hline$\alpha_{w}$ & beta & 0.50 & 0.10 & 0.393 & 0.498 & 0.604 \\
\hline$\omega$ & gamma & 1.50 & 0.30 & 1.050 & 1.534 & 2.024 \\
\hline$\omega^{\prime}$ & gamma & 1.50 & 0.30 & 1.083 & 1.513 & 1.993 \\
\hline$\omega^{\prime \prime}$ & gamma & 1.50 & 0.30 & 1.011 & 1.501 & 1.970 \\
\hline \multicolumn{7}{|c|}{ Czech Republic } \\
\hline$\zeta$ & gamma & 2.00 & 0.25 & 1.383 & 1.712 & 2.039 \\
\hline$\phi$ & gamma & 2.00 & 0.25 & 1.540 & 1.938 & 2.325 \\
\hline$h$ & beta & 0.70 & 0.10 & 0.453 & 0.564 & 0.671 \\
\hline$\sigma$ & beta & 0.60 & 0.10 & 0.631 & 0.703 & 0.774 \\
\hline$\eta$ & beta & 0.50 & 0.10 & 0.393 & 0.505 & 0.623 \\
\hline$\alpha_{w}$ & beta & 0.50 & 0.10 & 0.457 & 0.567 & 0.678 \\
\hline$\omega$ & gamma & 1.50 & 0.30 & 1.186 & 1.695 & 2.201 \\
\hline$\omega^{\prime}$ & gamma & 1.50 & 0.30 & 1.063 & 1.567 & 2.066 \\
\hline$\omega^{\prime \prime}$ & gamma & 1.50 & 0.30 & 1.039 & 1.536 & 2.032 \\
\hline \multicolumn{7}{|c|}{ Euro Area } \\
\hline$\zeta$ & gamma & 2.00 & 0.25 & 1.403 & 1.733 & 2.060 \\
\hline$\phi$ & gamma & 2.00 & 0.25 & 1.535 & 1.930 & 2.321 \\
\hline$h$ & beta & 0.70 & 0.10 & 0.336 & 0.486 & 0.645 \\
\hline$\sigma$ & beta & 0.60 & 0.10 & 0.636 & 0.714 & 0.792 \\
\hline$\eta$ & beta & 0.50 & 0.10 & 0.293 & 0.433 & 0.578 \\
\hline$\alpha_{w}$ & beta & 0.50 & 0.10 & 0.144 & 0.220 & 0.290 \\
\hline$\omega$ & gamma & 1.50 & 0.30 & 1.126 & 1.781 & 2.306 \\
\hline$\omega^{\prime}$ & gamma & 1.50 & 0.30 & 1.094 & 1.613 & 2.134 \\
\hline$\omega^{\prime \prime}$ & gamma & 1.50 & 0.30 & 1.063 & 1.574 & 2.072 \\
\hline
\end{tabular}

Although the model structure and the prior distributions of parameters are basically the same for all considered economies, there are some important differences in the posterior point estimates of the labour market parameters. The degree of wage rigidity in both CEE countries is rather comparable, 
but lower than in the EA, which seems to be quite reasonable (see Kolasa 2009 and Gradzewicz and Makarski 2013). The estimate of parameters describing the elasticity of the matching process with respect to unemployment in the Czech Republic resemble more the one observed in the EA. While in the Polish economy this elasticity is relatively low, the opposite is true for the Czech Republic and the Eurozone. Moreover, the point estimates indicate that the employees in Poland have higher bargaining power than in the Czech Republic and the EA 7 .

Table 3: Estimation results - shocks' persistence

\begin{tabular}{|c|c|c|c|c|c|c|}
\hline & \multicolumn{3}{|c|}{ Prior distribution } & \multicolumn{3}{|c|}{ Posterior distribution } \\
\hline & Type & Mean & $\mathrm{SD}$ & $5 \%$ & Mean & $95 \%$ \\
\hline \multicolumn{7}{|c|}{ Poland } \\
\hline$\rho_{\beta}$ & beta & 0.50 & 0.20 & 0.105 & 0.288 & 0.459 \\
\hline$\rho_{z}$ & beta & 0.50 & 0.20 & 0.656 & 0.778 & 0.904 \\
\hline$\rho_{g}$ & beta & 0.58 & 0.01 & 0.563 & 0.580 & 0.596 \\
\hline$\rho_{y}$ & beta & 0.90 & 0.01 & 0.889 & 0.904 & 0.920 \\
\hline$\rho_{\varrho}$ & beta & 0.50 & 0.20 & 0.288 & 0.449 & 0.614 \\
\hline$\rho_{v}$ & beta & 0.50 & 0.20 & 0.801 & 0.865 & 0.932 \\
\hline$\rho_{\eta}$ & beta & 0.50 & 0.20 & 0.032 & 0.148 & 0.256 \\
\hline \multicolumn{7}{|c|}{ Czech Republic } \\
\hline$\rho_{\beta}$ & beta & 0.50 & 0.20 & 0.122 & 0.297 & 0.468 \\
\hline$\rho_{z}$ & beta & 0.50 & 0.20 & 0.743 & 0.835 & 0.925 \\
\hline$\rho_{g}$ & beta & 0.55 & 0.01 & 0.534 & 0.550 & 0.566 \\
\hline$\rho_{y}$ & beta & 0.90 & 0.01 & 0.888 & 0.903 & 0.919 \\
\hline$\rho_{\varrho}$ & beta & 0.50 & 0.20 & 0.476 & 0.620 & 0.760 \\
\hline$\rho_{v}$ & beta & 0.50 & 0.20 & 0.825 & 0.887 & 0.950 \\
\hline$\rho_{\eta}$ & beta & 0.50 & 0.20 & 0.028 & 0.133 & 0.232 \\
\hline \multicolumn{7}{|c|}{ Euro Area } \\
\hline$\rho_{\beta}$ & beta & 0.50 & 0.20 & 0.477 & 0.644 & 0.814 \\
\hline$\rho_{z}$ & beta & 0.50 & 0.20 & 0.713 & 0.786 & 0.860 \\
\hline$\rho_{g}$ & beta & 0.88 & 0.01 & 0.863 & 0.880 & 0.896 \\
\hline$\rho_{y}$ & beta & 0.86 & 0.01 & 0.847 & 0.863 & 0.876 \\
\hline$\rho_{\varrho}$ & beta & 0.50 & 0.20 & 0.594 & 0.721 & 0.853 \\
\hline$\rho_{v}$ & beta & 0.50 & 0.20 & 0.837 & 0.894 & 0.950 \\
\hline$\rho_{\eta}$ & beta & 0.50 & 0.20 & 0.084 & 0.236 & 0.384 \\
\hline
\end{tabular}

\footnotetext{
${ }^{7}$ These results are robust to alternative specifications of prior distributions. Details on robustness checks are available upon request.
} 
The estimate of the relative risk aversion coefficient and the Frisch elasticity of the labour supply are similar in each considered economy. The dataset is rather uninformative on the elasticities of substitution in the consumption, investment and exports functions and the posterior distributions of these parameters are very similar to their prior equivalents.

Generally, the magnitude of the shocks hitting Polish and Czech economies is substantially larger than the size of shocks identified for the EA. The shocks in the Eurozone are, however, more persistent.

Table 4: Estimation results - shocks' standard deviations

\begin{tabular}{|c|c|c|c|c|c|c|}
\hline & \multicolumn{3}{|c|}{ Prior distribution } & \multicolumn{3}{|c|}{ Posterior distribution } \\
\hline & Type & Mean & $\mathrm{SD}$ & $5 \%$ & Mean & $95 \%$ \\
\hline \multicolumn{7}{|c|}{ Poland } \\
\hline$\epsilon_{\beta}$ & inv. gamma & 0.01 & $\inf$ & 0.013 & 0.020 & 0.025 \\
\hline$\epsilon_{z}$ & inv. gamma & 0.01 & $\inf$ & 0.005 & 0.006 & 0.007 \\
\hline$\epsilon_{g}$ & inv. gamma & 0.01 & $\inf$ & 0.009 & 0.011 & 0.012 \\
\hline$\epsilon_{y}$ & inv. gamma & 0.01 & $\inf$ & 0.005 & 0.006 & 0.006 \\
\hline$\epsilon_{\varrho}$ & inv. gamma & 0.10 & $\inf$ & 0.090 & 0.107 & 0.123 \\
\hline$\epsilon_{v}$ & inv. gamma & 0.10 & $\inf$ & 0.090 & 0.117 & 0.143 \\
\hline$\epsilon_{\eta}$ & inv. gamma & 0.10 & $\inf$ & 0.093 & 0.190 & 0.283 \\
\hline \multicolumn{7}{|c|}{ Czech Republic } \\
\hline$\epsilon_{\beta}$ & inv. gamma & 0.01 & $\inf$ & 0.023 & 0.033 & 0.043 \\
\hline$\epsilon_{z}$ & inv. gamma & 0.01 & $\inf$ & 0.006 & 0.007 & 0.008 \\
\hline$\epsilon_{g}$ & inv. gamma & 0.01 & $\inf$ & 0.016 & 0.018 & 0.021 \\
\hline$\epsilon_{y}$ & inv. gamma & 0.01 & $\inf$ & 0.005 & 0.006 & 0.006 \\
\hline$\epsilon_{\varrho}$ & inv. gamma & 0.10 & $\inf$ & 0.066 & 0.078 & 0.089 \\
\hline$\epsilon_{v}$ & inv. gamma & 0.10 & $\inf$ & 0.119 & 0.142 & 0.163 \\
\hline$\epsilon_{\eta}$ & inv. gamma & 0.10 & $\inf$ & 0.093 & 0.165 & 0.235 \\
\hline \multicolumn{7}{|c|}{ Euro Area } \\
\hline$\epsilon_{\beta}$ & inv. gamma & 0.01 & $\inf$ & 0.008 & 0.014 & 0.020 \\
\hline$\epsilon_{z}$ & inv. gamma & 0.01 & $\inf$ & 0.004 & 0.005 & 0.005 \\
\hline$\epsilon_{g}$ & inv. gamma & 0.01 & $\inf$ & 0.003 & 0.003 & 0.003 \\
\hline$\epsilon_{y}$ & inv. gamma & 0.01 & $\inf$ & 0.005 & 0.006 & 0.007 \\
\hline$\epsilon_{\varrho}$ & inv. gamma & 0.10 & $\inf$ & 0.030 & 0.035 & 0.040 \\
\hline$\epsilon_{v}$ & inv. gamma & 0.10 & $\inf$ & 0.050 & 0.061 & 0.071 \\
\hline$\epsilon_{\eta}$ & inv. gamma & 0.10 & $\inf$ & 0.094 & 0.196 & 0.295 \\
\hline
\end{tabular}




\section{Results}

\subsection{Model's data fit}

In order to assess the ability of the model to reflect the data dynamics, we compare the theoretical moments generated by the model with those observed in the data, see Table 5 . The time series of the labour wedge is calculated using the data on consumption, employment and output and the posterior means of parameters from the utility function.

Table 5: Comparison of theoretical moments and moments from the data

\begin{tabular}{|c|c|c|c|c|c|c|}
\hline & \multicolumn{2}{|c|}{ Standard deviation } & \multicolumn{2}{|c|}{ Correlation wih GDP } & \multicolumn{2}{|c|}{ Autocorrelation } \\
\hline & Model & Data & Model & Data & Model & Data \\
\hline \multicolumn{7}{|c|}{ Poland } \\
\hline$Y$ & 0.018 & 0.014 & 1.000 & 1.000 & 0.922 & 0.883 \\
\hline$C$ & 0.014 & 0.011 & 0.592 & 0.798 & 0.829 & 0.746 \\
\hline$U$ & 0.010 & 0.013 & -0.559 & -0.729 & 0.942 & 0.945 \\
\hline$V$ & 0.209 & 0.177 & 0.071 & 0.492 & 0.697 & 0.881 \\
\hline$w$ & 0.016 & 0.013 & 0.484 & 0.488 & 0.770 & 0.739 \\
\hline$g$ & 0.013 & 0.014 & -0.009 & 0.308 & 0.580 & 0.585 \\
\hline$Y^{*}$ & 0.013 & 0.012 & 0.396 & 0.705 & 0.904 & 0.896 \\
\hline wedge & 0.037 & 0.049 & 0.415 & 0.668 & 0.746 & 0.869 \\
\hline \multicolumn{7}{|c|}{ Czech Republic } \\
\hline$Y$ & 0.022 & 0.019 & 1.000 & 1.000 & 0.936 & 0.891 \\
\hline$C$ & 0.017 & 0.011 & 0.557 & 0.462 & 0.853 & 0.652 \\
\hline$U$ & 0.007 & 0.008 & -0.349 & -0.630 & 0.930 & 0.915 \\
\hline$V$ & 0.272 & 0.289 & 0.202 & 0.806 & 0.789 & 0.926 \\
\hline$w$ & 0.020 & 0.017 & 0.638 & 0.699 & 0.742 & 0.692 \\
\hline$g$ & 0.022 & 0.022 & -0.014 & -0.463 & 0.550 & 0.550 \\
\hline$Y^{*}$ & 0.013 & 0.013 & 0.472 & 0.879 & 0.903 & 0.898 \\
\hline wedge & 0.041 & 0.039 & 0.072 & 0.192 & 0.478 & 0.423 \\
\hline \multicolumn{7}{|c|}{ Euro Area } \\
\hline$Y$ & 0.012 & 0.012 & 1.000 & 1.000 & 0.912 & 0.896 \\
\hline$C$ & 0.011 & 0.006 & 0.545 & 0.785 & 0.910 & 0.852 \\
\hline$U$ & 0.004 & 0.005 & -0.435 & -0.852 & 0.936 & 0.935 \\
\hline$V$ & 0.134 & 0.149 & 0.168 & 0.822 & 0.760 & 0.957 \\
\hline$w$ & 0.008 & 0.003 & 0.688 & 0.248 & 0.935 & 0.804 \\
\hline$g$ & 0.006 & 0.006 & -0.013 & -0.378 & 0.880 & 0.877 \\
\hline$Y^{*}$ & 0.012 & 0.012 & 0.347 & 0.605 & 0.863 & 0.861 \\
\hline wedge & 0.022 & 0.016 & 0.245 & 0.610 & 0.700 & 0.730 \\
\hline
\end{tabular}


Given the purpose of this study, we focus mainly on the model's ability to match the moments of the labour market variables, i.e. the unemployment rate, the number of vacancies, real wages and the labour wedge. All in all, although the data fit is not ideal, the general patterns observed in the data are well reflected by our model.

The model performs relatively well in capturing the volatilities of the unemployment rate, vacancies and wage per employee for all three economies. The only exception here is the standard deviation of the real wage in the EA, which is overestimated by the model. The model does a good job in capturing the sign of the correlation between output and the labour market variables. However, it is fair to remark that the model has some problems with reflecting the strength of these relationships. The persistence of these variables is roughly captured.

Although the model somewhat underestimates the volatility of the labour wedge in Poland and overestimates it in the EA and, to lesser extent, in the Czech Republic, the volatility implied by the model is still lower in the Eurozone than in the CEE countries, as in the data. The model also manages to generate procyclicality in the labour wedge in both the EA and the CEE region. The strength of implied correlation between GDP and the wedge is, however, too small in all economies. Nevertheless, consistently with the data, the model implies the highest wedge procyclicality in Poland and the lowest in the Czech Republic. The persistence of the labour wedge is well reflected in all three models.

\subsection{Shocks driving the labour wedge}

In order to identify the forces driving fluctuations of the labour wedge, we look at its variance decomposition for four different horizons. The contributions of each of the structural shocks to the forecast error variance are reported in Table 6. The parameters of the simulated model correspond to their posterior means.

Roughly speaking, the labour wedge variability both in the CEE region and in the EA is explained by the consumption preference shock and two labour market disturbances affecting vacancy posting cost and job destruction rate. However, the contributions of these shocks differ across three countries.

In the EA the main factor responsible for the volatility of the gap between MRS and MPL is the consumption preference shock. Although its role decreases with the forecast horizon, it still accounts for more than $53 \%$ of forecast error in the long run, which is much higher than the joint impact of both labour market shocks. In the shorter horizon, the role of the separation shock appears to be greater than the role of the hiring cost shock, but in the long run, the importance of these two labour market disturbances seems to be comparable.

The variance decomposition of the labour wedge differs significantly across the CEE economies. In the Czech Republic, the preference shock is the most important determinant to the labour wedge fluctuations over all considered forecast horizons and the role of the labour market disturbances is 
even less important than in the Eurozone. In the long run, vacancy posting cost and separation rate disturbances account together for only $24 \%$ of the wedge volatility.

Table 6: Variance decomposition of the labour wedge (in\%)

\begin{tabular}{lllll}
\hline & $2 \mathrm{q}$ & $4 \mathrm{q}$ & $10 \mathrm{q}$ & $40 \mathrm{q}$ \\
\hline Poland & & & & \\
Productivity shock & 5.8 & 5.0 & 3.4 & 3.0 \\
Consumption preference shock & 65.9 & 47.5 & 31.4 & 27.8 \\
Government spending shock & 0.0 & 0.0 & 0.0 & 0.0 \\
Foreign output shock & 1.5 & 2.5 & 3.6 & 4.2 \\
Separation rate shock & 22.7 & 27.6 & 22.1 & 19.6 \\
Bargaining power shock & 0.6 & 1.5 & 1.5 & 1.4 \\
Hiring cost shock & 3.6 & 15.9 & 38.0 & 43.9 \\
Czech Republic & & & & \\
Productivity shock & 3.9 & 4.7 & 4.8 & 4.7 \\
Consumption preference shock & 88.6 & 80.1 & 71.1 & 68.4 \\
Government spending shock & 0.1 & 0.1 & 0.0 & 0.0 \\
Foreign output shock & 0.3 & 1.0 & 2.1 & 2.8 \\
Separation rate shock & 6.0 & 9.4 & 9.8 & 9.5 \\
Bargaining power shock & 0.1 & 0.1 & 0.2 & 0.1 \\
Hiring cost shock & 1.0 & 4.7 & 12.0 & 14.5 \\
Euro Area & & & & \\
Productivity shock & 4.1 & 3.4 & 2.8 & 2.8 \\
Consumption preference shock & 79.2 & 70.1 & 58.0 & 53.5 \\
Government spending shock & 0.2 & 0.2 & 0.1 & 0.1 \\
Foreign output shock & 5.9 & 5.9 & 8.6 & 11.7 \\
Separation rate shock & 9.2 & 14.6 & 16.7 & 15.7 \\
Bargaining power shock & 0.4 & 1.4 & 2.1 & 2.0 \\
Hiring cost shock & 1.2 & 4.6 & 11.5 & 14.2 \\
\hline
\end{tabular}

In contrast to the Czech Republic, the labour market shocks play a crucial role for the MRS-MPL gap fluctuations in Poland. They are still less important than the preference shock in the short run, but in the long run they are the main driving force behind the labour wedge and account for more than $64 \%$ of its volatility.

Overall, while the sources of the labour wedge fluctuations in Poland and the EA differ significantly, the Czech Republic stands out as more similar to the EA in terms of the sources of MRS-MPL gap fluctuations. 


\subsection{Structural vs. stochastic heterogeneity}

In this subsection we investigate to what extent higher volatility of the labour wedge in the CEE countries results from the country-specific shocks (the persistence and the magnitude of shocks), and to what extent from the structure of their economies (captured by the structural parameters). For this purpose, we check what the hypothetical volatility of the labour wedge in the CEE countries would be if these economies were hit by the EA-specific shocks. The results of simulations summarized in Table 7 are based on the posterior means of estimated parameters.

\begin{tabular}{lll} 
Table 7: Labour wedge volatility, counterfactual simulations (shocks structure as in the EA) & PL \\
\hline Data & 0.0493 & 0.0391 \\
Country model & 0.0371 & 0.0405 \\
Productivity shock as in the EA & 0.0369 & 0.0399 \\
Consumption preference shock as in the EA & 0.0356 & 0.0286 \\
Government spending shock as in the EA & 0.0371 & 0.0405 \\
Foreign output shock as in the EA & 0.0367 & 0.0402 \\
Separation rate shock as in the EA & 0.0343 & 0.0392 \\
Bargaining power shock as in the EA & 0.0373 & 0.0406 \\
Hiring cost shock as in the EA & 0.0312 & 0.0381 \\
Labour market shocks as in the EA & 0.0280 & 0.0367 \\
Euro Area shocks (all) & 0.0250 & 0.0211 \\
\hline
\end{tabular}

The results presented in Table 7 confirm relatively bigger role of the labour market disturbances for the labour wedge dynamics in Poland. Moreover, we can see that the CEE countries would experience much lower labour wedge volatility if all shocks in this region had the same characteristics as in the Eurozone (the standard deviation drops from 0.037 to 0.025 in case of Poland and from 0.041 to 0.021 in case of the Czech Republic). Therefore, we can state that the characteristics of stochastic disturbances contribute strongly to the relatively high variability of the labour wedge in Poland and the Czech Republic.

Interestingly, if shocks were the same, the labour wedge variability in the Czech Republic would be even lower than in the EA (standard deviation equal to 0.021 vs. 0.022 in the EA), while in Poland the wedge would be still more volatile (standard deviation equal to 0.025). Thus, it might be noteworthy to determine the reasons for different response of Polish and Czech economies.

While a part of this heterogeneity might result from different households' preferences, our focus is on the role of three labour market characteristics, such as the elasticity of matches to unemployment $\sigma$, workers' bargaining power $\eta$ and the degree of real wage rigidity $\alpha_{w}$. In order to identify the impact of 
these parameters on the wedge volatility, we check what the model-implied standard deviations of the labour wedge would be if these parameters were set at the levels identified for the Eurozone, leaving everything else, including the stochastic characteristics, as in the country-specific model. The results of such simulations are presented in Table 8. Again the parameters of the simulated models correspond to their posterior means.

Table 8: Labour wedge volatility, counterfactual simulations (labour market parameters as in the EA)

\begin{tabular}{lllll}
\hline & Parameters & & Labour wedge volatility \\
\hline Poland & & & \\
Country model & $\sigma=0.55$ & $\eta=0.62$ & $\alpha_{w}=0.50$ & 0.0371 \\
$\sigma$ as in the EA & $\sigma=0.71$ & $\eta=0.62$ & $\alpha_{w}=0.50$ & 0.0327 \\
$\eta$ as in the EA & $\sigma=0.55$ & $\eta=0.43$ & $\alpha_{w}=0.50$ & 0.0327 \\
$\alpha_{w}$ as in the EA & $\sigma=0.55$ & $\eta=0.62$ & $\alpha_{w}=0.22$ & 0.0376 \\
$\sigma, \eta, \alpha_{w}$ as in the EA & $\sigma=0.71$ & $\eta=0.43$ & $\alpha_{w}=0.22$ & 0.0308 \\
Czech Republic & & & & \\
Country model & $\sigma=0.70$ & $\eta=0.51$ & $\alpha_{w}=0.57$ & 0.0405 \\
$\sigma$ as in the EA & $\sigma=0.71$ & $\eta=0.51$ & $\alpha_{w}=0.57$ & 0.0403 \\
$\eta$ as in the EA & $\sigma=0.70$ & $\eta=0.43$ & $\alpha_{w}=0.57$ & 0.0403 \\
$\alpha_{w}$ as in the EA & $\sigma=0.70$ & $\eta=0.51$ & $\alpha_{w}=0.22$ & 0.0406 \\
$\sigma, \eta, \alpha_{w}$ as in the EA & $\sigma=0.71$ & $\eta=0.43$ & $\alpha_{w}=0.23$ & 0.0401 \\
\hline
\end{tabular}

The results presented in Table 8 indicate that lower, as compared to the Eurozone, elasticity of matches to unemployment and higher workers' bargaining power contribute to relatively high volatility of the wedge in Poland. Their impact on differences vis-à-vis the EA in the Czech economy is, however, rather negligible. More flexible wages in the CEE region (higher $\alpha_{w}$ ) seem to play a minor role for the wedge volatility. Setting all three considered labour market parameters at the levels identified for the Eurozone lowers the variability of the labour wedge in Poland significantly (standard deviation drops from 0.0371 to 0.0308 ), but it basically does not affect its dynamics in the Czech Republic (standard deviation decreases slightly from 0.0405 to 0.0401). Thus, although the observed higher volatility of the labour wedge in both CEE economies reflects mainly different characteristics of stochastic disturbances, structural labour market features in Poland also matter.

\subsection{Discussion}

The analysis of the variance decomposition has shown that the considered countries differ significantly in terms of sources of wedge fluctuations. The results of simulations presented in Table 9 indicate that smaller role of the preference shock in Poland follows not only from heterogeneity in the stochastic structure, but also from differences in the structural parameters. Setting the labour market 
parameters (or, more specifically, the elasticity of the matching function and the workers' bargaining power) at the levels identified for the EA amplifies the contribution of the preference shock to the wedge variance in longer time horizons, which indicates that the structural features of the labour market affect the way in which the preference shock propagates through the economy. The heterogeneity in other structural parameters seems to play only a minor role for the differences in the contribution of the preference shock to the wedge dynamics.

Table 9: Contribution of the preference shock to the wedge variance in Poland, counterfactual simulations (in\% )

\begin{tabular}{lllll}
\hline & $2 \mathrm{q}$ & $4 \mathrm{q}$ & $10 \mathrm{q}$ & $40 \mathrm{q}$ \\
\hline Country model & 65.9 & 47.5 & 31.4 & 27.8 \\
$\sigma$ as in the EA & 66.7 & 51.5 & 39.2 & 36.1 \\
$\eta$ as in the EA & 67.8 & 52.3 & 38.6 & 35.6 \\
$\alpha_{w}$ as in the EA & 65.9 & 47.0 & 30.6 & 27.2 \\
$\sigma, \eta, \alpha_{w}$ as in the EA & 67.5 & 53.4 & 42.8 & 40.6 \\
All structural parameters as in the EA & 67.5 & 53.5 & 42.9 & 40.8 \\
\hline
\end{tabular}

Although the preference shock is very important in DSGE models as it helps to match the data dynamics and proves itself to be a significant driver of aggregate fluctuations, many authors claim that its nature is dubiously structural (see, e.g., Chari et al.|2009). However, more recent studies argue that it is possible to give the preference shock a plausible structural interpretation. According to Fisher (2015), the preference shock can be reinterpreted as a structural shock to the demand for safe and/or liquid assets. The similar interpretation is used by Christiano et al. (2015). This liquidity demand shock transmits through the economy like a financial shock and therefore captures the disturbances originating in the financial sector (Anzoategui et al. 2015). This interpretation of the preference shock seems to be relevant in case of our analysis. While the Polish financial sector was relatively stable and sound in the considered period, the financial sectors in the EA and the Czech Republic experienced some difficulties.

Poland turned out to be relatively resilient to both the international financial crisis from the late 1990's and the recent global financial crisis. One of the factors which contributed to Poland's exceptional performance throughout the crisis was healthy banking sector, which remained liquid and well-capitalized.

The economic problems from the late 1990's, which Poland managed to avoid, strongly affected the Czech economy and led to deep currency and financial crisis. The troubles of the banking sector resulted from an accumulation of bad loans and lack of transparent financial market regulations. Since then, the Czech Republic went a long way towards restoring healthy banking sector and underwent fundamental restructuring. As a result, the financial crisis which erupted in 2008 did not harmed the 
Czech banks significantly and the Czech financial sector served as a source of stability for the Czech economy during that period (Dubská 2013). On the contrary, the global financial crisis caused a severe turmoil in the financial system of many EA member states and its negative consequences in the EA are still noticeable.

Unlike the financial sector, the Polish labour market experienced some difficulties in the analysed period. The economic transformation in Poland resulted in high structural unemployment, which Poland was unable to reduce for many years. Although many problems of the Polish labour market have been already solved, there are a lot of challenges waiting ahead. For example, the country still needs to alleviate the existing duality of the labour market and find the balance between employment protection and labour market flexibility (World Bank 2015). Moreover, our results suggest that the efficiency of the Polish labour market in the matching process is relatively low (see parameters in Table 1).

All these factors seem to explain the differences in the labour wedge variance decomposition across analysed countries and justify the interpretation of the preference shock as the one capturing disturbances from the financial sector. Overall, our results suggest that the labour wedge movements and hence the welfare costs of business cycle fluctuations (Galí et al. 2007) in Poland are connected with inefficient functioning of the labour market. To the contrary, wedge fluctuations in Czech Republic and the EA seem to result from the financial frictions.

\section{Conclusions}

This paper aims to shed more light on the differences between the labour wedge fluctuations in the CEE countries and the Euro Area. To this end, we construct a DSGE model of a small open economy with search and matching frictions on the labour market and estimate it separately for two CEE representatives, namely Poland and the Czech Republic, and the Eurozone. The estimated models succeed in replicating the general pattern of the labour wedge behaviour, including its procyclicality and higher volatility in the CEE region than in the EA.

Our results indicate that the sources of wedge dynamics and hence the welfare costs of business cycle fluctuations differ significantly across the CEE countries and the Eurozone. While the gap between MRS and MPL in Poland is driven largely by the labour market disturbances, the consumption preference shock appears to be the main driving force of its fluctuations in the EA and the Czech Republic.

Furthermore, we find that the distinct characteristics of stochastic disturbances are the main source of higher volatilities of the labour wedge in the CEE countries. However, in Poland the country-specific structural features of the labour market also play a role for its fluctuations. More specifically, the values 
of the elasticity of the matching process with respect to unemployment and workers' bargaining power enlarge the differences between the wedge variability in Poland and the EA. The impact of these parameters in the Czech Republic is rather marginal.

All in all, we find heterogeneity in the labour wedge fluctuations within the CEE region. The Czech Republic seems to resemble more the EA in terms of both wedge volatility and its driving forces. Our results suggest that the labour market disturbances in Poland are relatively more severe. By contrast, the Czech Republic and the EA seem to be characterized by greater financial frictions.

\section{References}

Adolfson, M., Laséen, S., Lindé, J. and Villani, M.: 2007, Bayesian estimation of an open economy DSGE model with incomplete pass-through, 72(2), 481-511.

Anzoategui, D., Comin, D., Gertler, M. and Martinez, J.: 2015, Endogenous Technology Adoption and R\&D as Sources of Business Cycle Persistence, mimeo.

Blanchard, O. and Galí, J.: 2010, Labor Markets and Monetary Policy: A New Keynesian Model with Unemployment, American Economic Journal: Macroeconomics 2(2), 1-30.

Brooks, S. P. and Gelman, A.: 1998, General methods for monitoring convergence of iterative simulations, Journal of Computational and Graphical Statistics 7(4), 434-455.

Brzoza-Brzezina, M., Jacquinot, P. and Kolasa, M.: 2014, Can We Prevent Boom-Bust Cycles During Euro Area Accession?, Open Economies Review 25(1), 35-69.

Bussière, M., Callegari, G., Ghironi, F., Sestieri, G. and Yamano, N.: 2013, Estimating Trade Elasticities: Demand Composition and the Trade Collapse of 2008-2009, American Economic Journal: Macroeconomics 5(3), 118-51.

Chari, V. V., Kehoe, P. J. and McGrattan, E. R.: 2002, Can Sticky Price Models Generate Volatile and Persistent Real Exchange Rates?, Review of Economic Studies 69(3), 533-563.

Chari, V. V., Kehoe, P. J. and McGrattan, E. R.: 2007, Business cycle accounting, Econometrica 75(3), 781-836.

Chari, V. V., Kehoe, P. J. and McGrattan, E. R.: 2009, New Keynesian Models: Not Yet Useful for Policy Analysis, American Economic Journal: Macroeconomics 1(1), 242-66.

Cheremukhin, A. A. and Restrepo-Echavarria, P.: 2014, The labor wedge as a matching friction, European Economic Review 68, 71-92. 
Christiano, L. J., Eichenbaum, M. S. and Trabandt, M.: 2015, Understanding the Great Recession, American Economic Journal: Macroeconomics 7(1), 110-67.

Christiano, L. J., Trabandt, M. and Walentin, K.: 2011, Introducing financial frictions and unemployment into a small open economy model, Journal of Economic Dynamics and Control 35(12), 19992041.

Christoffel, K., Kuester, K. and Linzert, T.: 2009, The role of labor markets for euro area monetary policy, European Economic Review 53(8), 908-936.

Dubská, D.: 2013, The czech banking sector: Two decades with the shuttle changes, Statistika: Statistics \& Economy Journal 93(1), 71-82.

Fisher, J. D.: 2015, On the Structural Interpretation of the Smets-Wouters "Risk Premium" Shock, Journal of Money Credit and Banking 47(2-3), 511-516.

Galí, J., Gertler, M. and López-Salido, J. D.: 2007, Markups Gaps, and the Welfare Costs of Business Fluctuations, Review of Economics and Statistics 89(1), 44-59.

Galí, J. and Monacelli, T.: 2005, Monetary Policy and Exchange Rate Volatility in a Small Open Economy, Review of Economic Studies 72(3), 707-734.

Gertler, M. and Trigari, A.: 2009, Unemployment Fluctuations with Staggered Nash Wage Bargaining, Journal of Political Economy 117(1), 38-86.

Gomes, S., Jacquinot, P. and Pisani, M.: 2012, The EAGLE. A model for policy analysis of macroeconomic interdependence in the euro area, Economic Modelling 29(5), 1686-1714.

Gradzewicz, M., Growiec, J. and Wyszyński, R.: 2012, Luka nieefektywności w cyklu koniunkturalnym w Polsce, National Bank of Poland Working Paper 281, National Bank of Poland, Economic Institute.

Gradzewicz, M. and Makarski, K.: 2013, The business cycle implications of the euro adoption in Poland, Applied Economics 45(17), 2443-2455.

Hall, R. E.: 1997, Macroeconomic Fluctuations and the Allocation of Time, Journal of Labor Economics 15(1), S223-S250.

Hall, R. E.: 2005, Employment Fluctuations with Equilibrium Wage Stickiness, American Economic Review 95(1), 50-65.

Hobijn, B. and Şahin, A.: 2009, Job-finding and separation rates in the $\{$ OECD $\}$, Economics Letters $\mathbf{1 0 4}(3), 107-111$. 
Karabarbounis, L.: 2014, The labor wedge: MRS vs. MPN, Review of Economic Dynamics 17(2), 206223.

Kolasa, M.: 2009, Structural heterogeneity or asymmetric shocks? Poland and the euro area through the lens of a two-country DSGE model, Economic Modelling 26(6), 1245-1269.

Kolasa, M.: 2013, Business cycles in EU new member states: How and why are they different?, Journal of Macroeconomics 38, 487-496.

Merz, M.: 1995, Search in the labor market and the real business cycle, Journal of Monetary Economics 36(2), 269-300.

Mortensen, D. T. and Pissarides, C. A.: 1994, Job Creation and Job Destruction in the Theory of Unemployment, The Review of Economic Studies 61(3), 397-415.

Moyen, S. and Sahuc, J. G.: 2005, Incorporating labour market frictions into an optimising-based monetary policy model, Economic Modelling 22(1), 159-186.

Pescatori, A. and Tasci, M.: 2011, Search frictions and the labor wedge, Working Paper 1111, Federal Reserve Bank of Cleveland.

Pissarides, C. A.: 1985, Short-run Equilibrium Dynamics of Unemployment Vacancies, and Real Wages, American Economic Review 75(4), 676-90.

Sala, L., Söderström, U. and Trigari, A.: 2010, The Output Gap, the Labor Wedge, and the Dynamic Behavior of Hours, CEPR Discussion Paper 8005, C.E.P.R. Discussion Papers.

Shimer, R.: 2005, The Cyclical Behavior of Equilibrium Unemployment and Vacancies, American Economic Review 95(1), 25-49.

Shimer, R.: 2009, Convergence in Macroeconomics: The Labor Wedge, American Economic Journal: Macroeconomics 1(1), 280-297.

Smets, F. and Wouters, R.: 2003, An Estimated Dynamic Stochastic General Equilibrium Model of the Euro Area, Journal of the European Economic Association 1(5), 1123-1175.

Stähler, N. and Thomas, C.: 2012, FiMod - A DSGE model for fiscal policy simulations, Economic Modelling 29(2), 239-261.

Trigari, A.: 2006, The Role of Search Frictions and Bargaining for Inflation Dynamics, Working Paper 304, IGIER (Innocenzo Gasparini Institute for Economic Research), Bocconi University.

World Bank: 2015, World Bank Group - Poland Partnership Program Snapshot. 


\section{Appendix}

Prior and posterior distributions

\section{Poland}
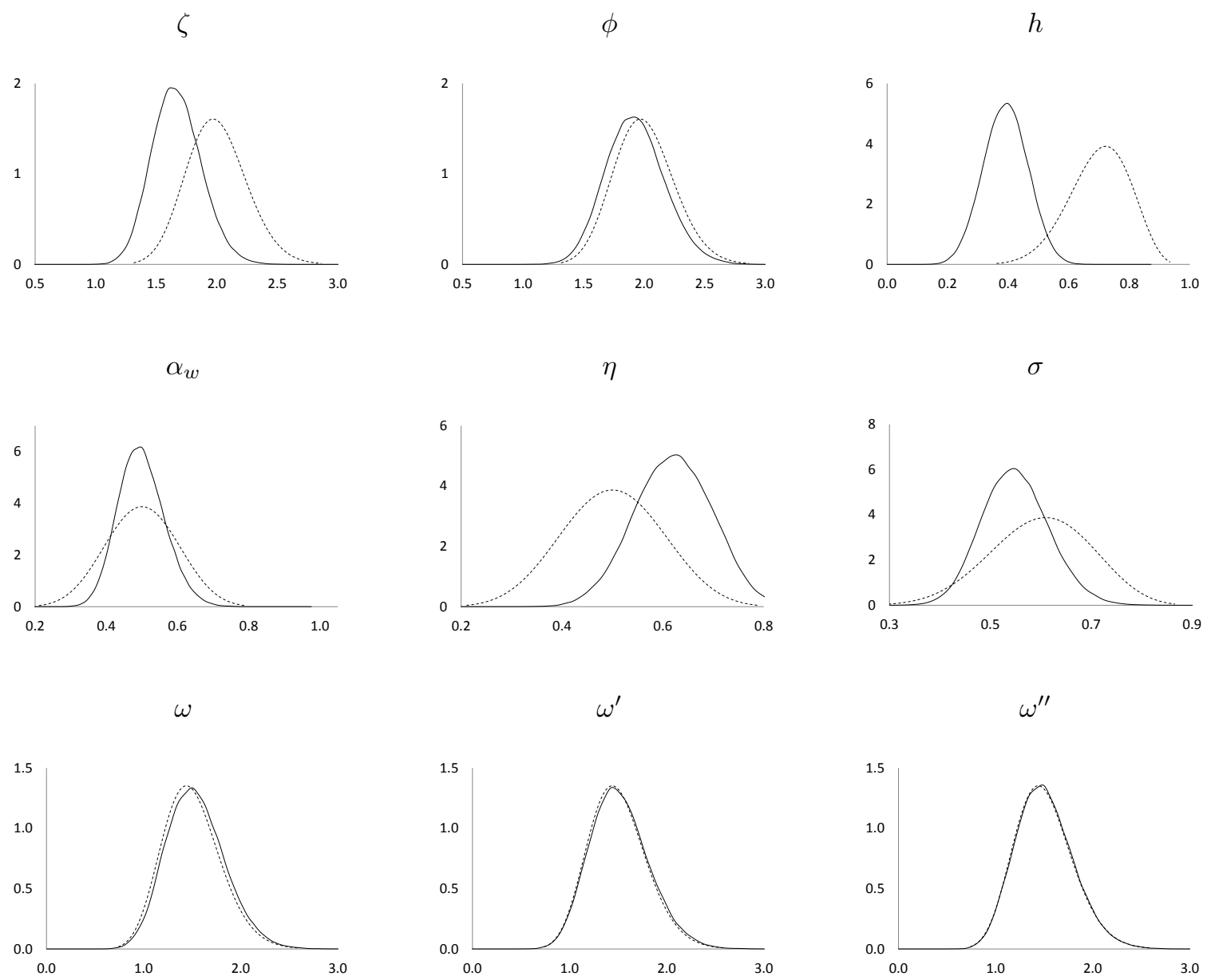

$\sigma_{z}$
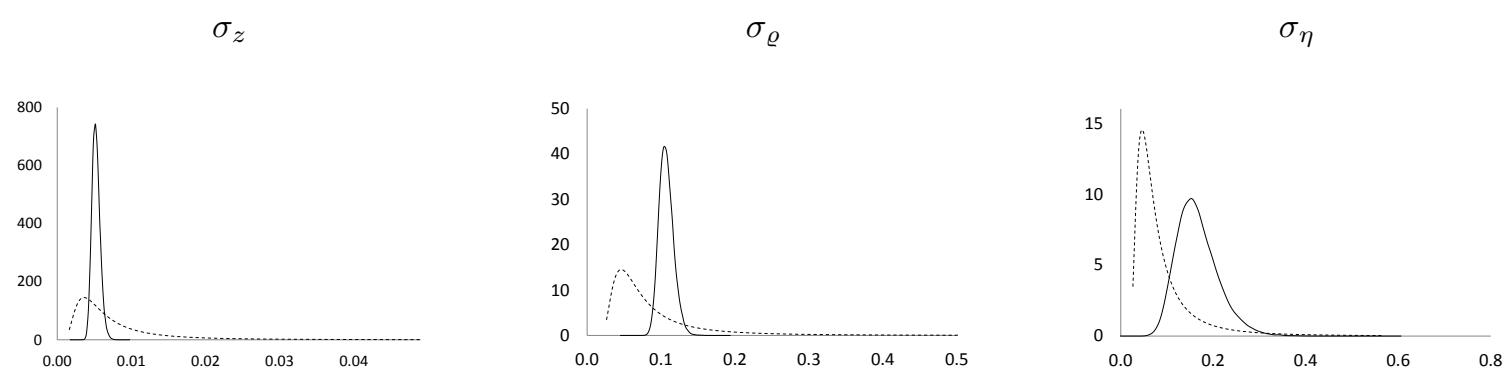
$\sigma_{g}$

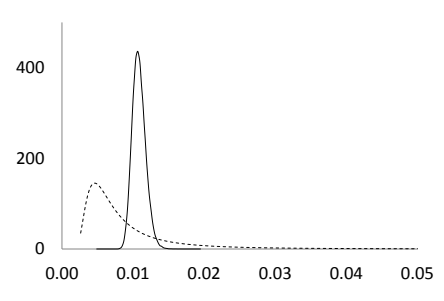

$\sigma_{y}$

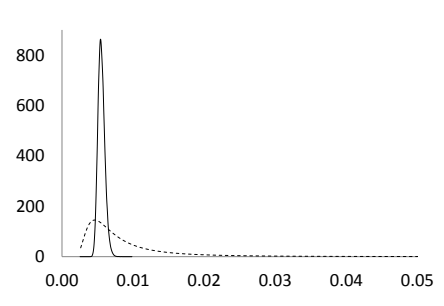

$\rho_{\eta}$

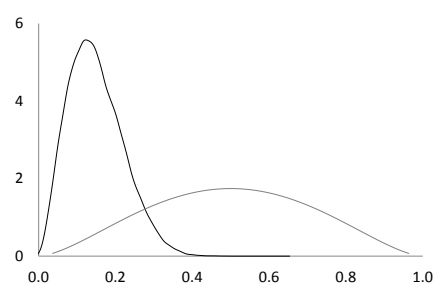

$\rho_{v}$

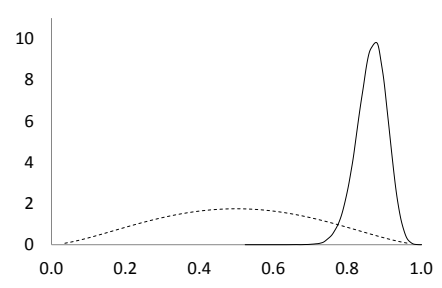

$\sigma_{\beta}$

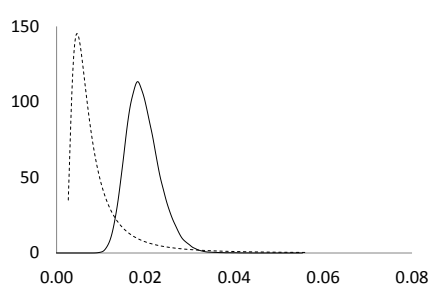

$\rho_{z}$

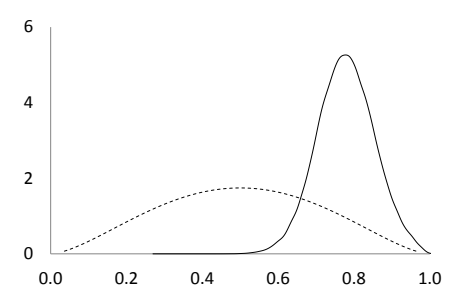

$\rho_{g}$

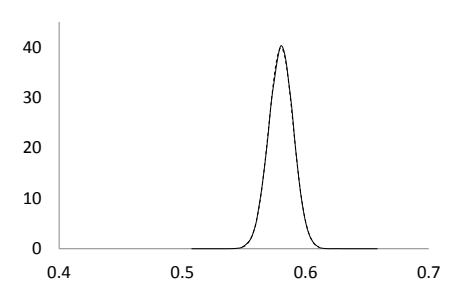

$\rho_{y}$

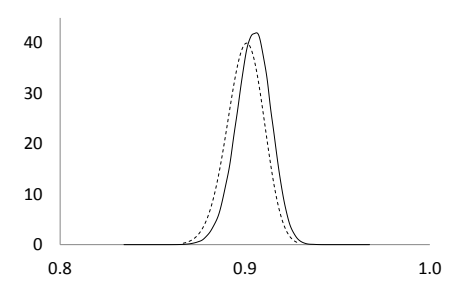

$\sigma_{v}$

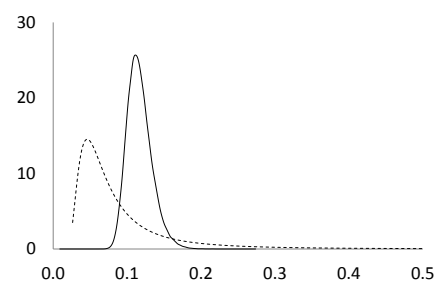

$\rho_{\varrho}$

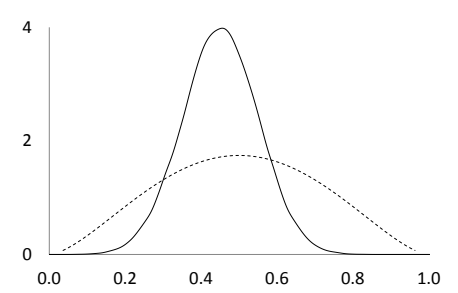

$\rho_{\beta}$

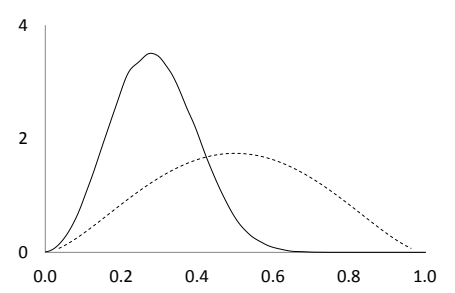




\section{Czech Republic}
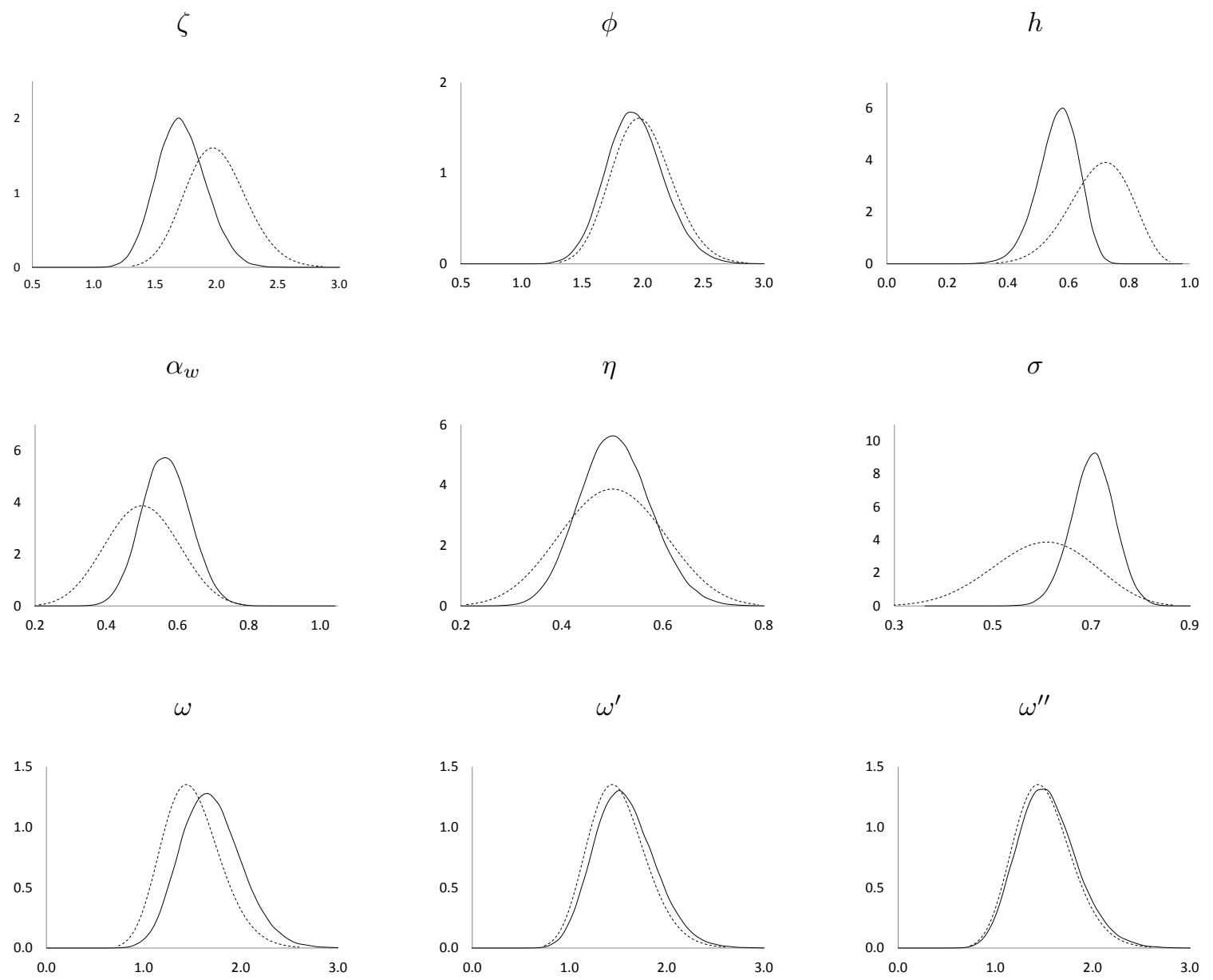

$\sigma_{z}$
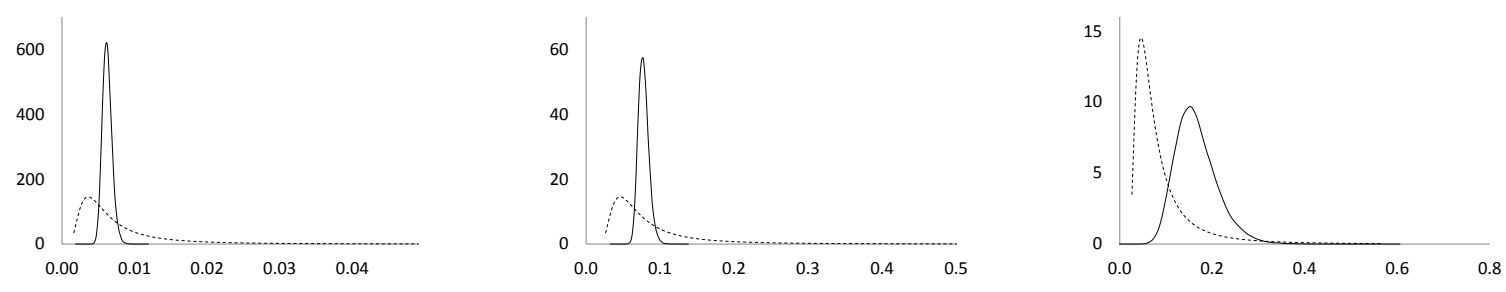

$\sigma_{g}$
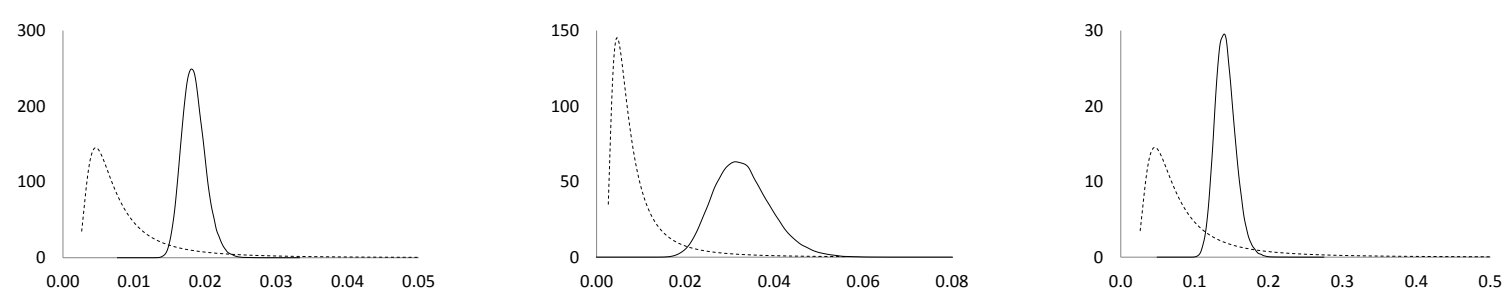
$\sigma_{y}$

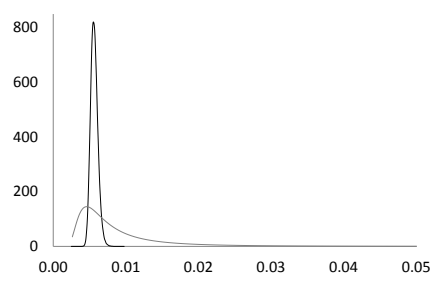

$\rho_{\eta}$

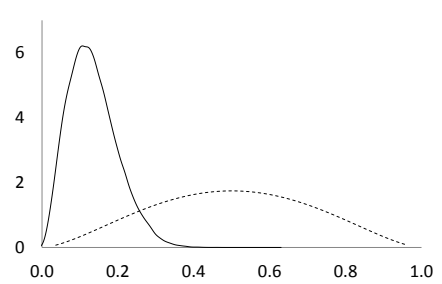

$\rho_{v}$

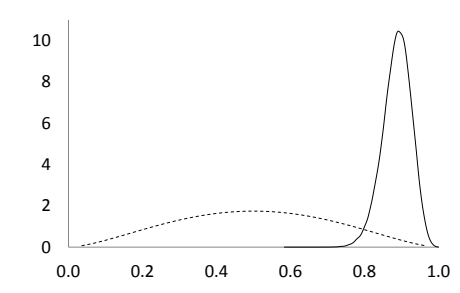

$\rho_{z}$

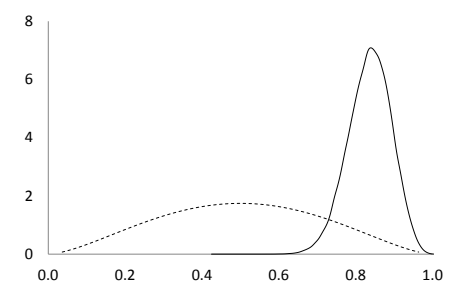

$\rho_{g}$

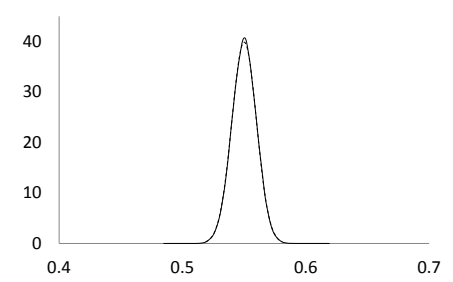

$\rho_{y}$

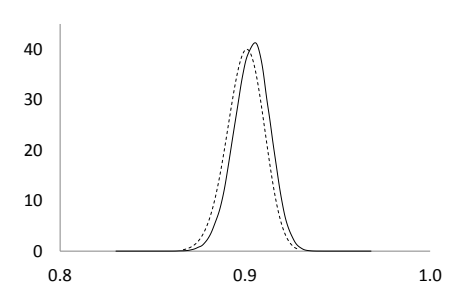

$\rho_{\varrho}$

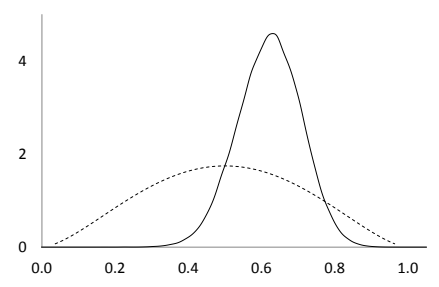

$\rho_{\beta}$

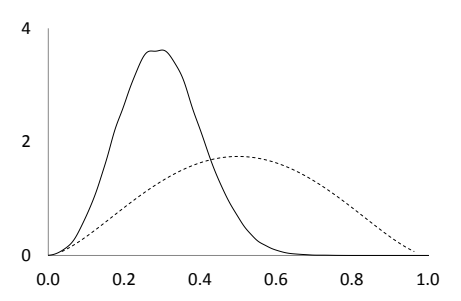




\section{Euro Area}
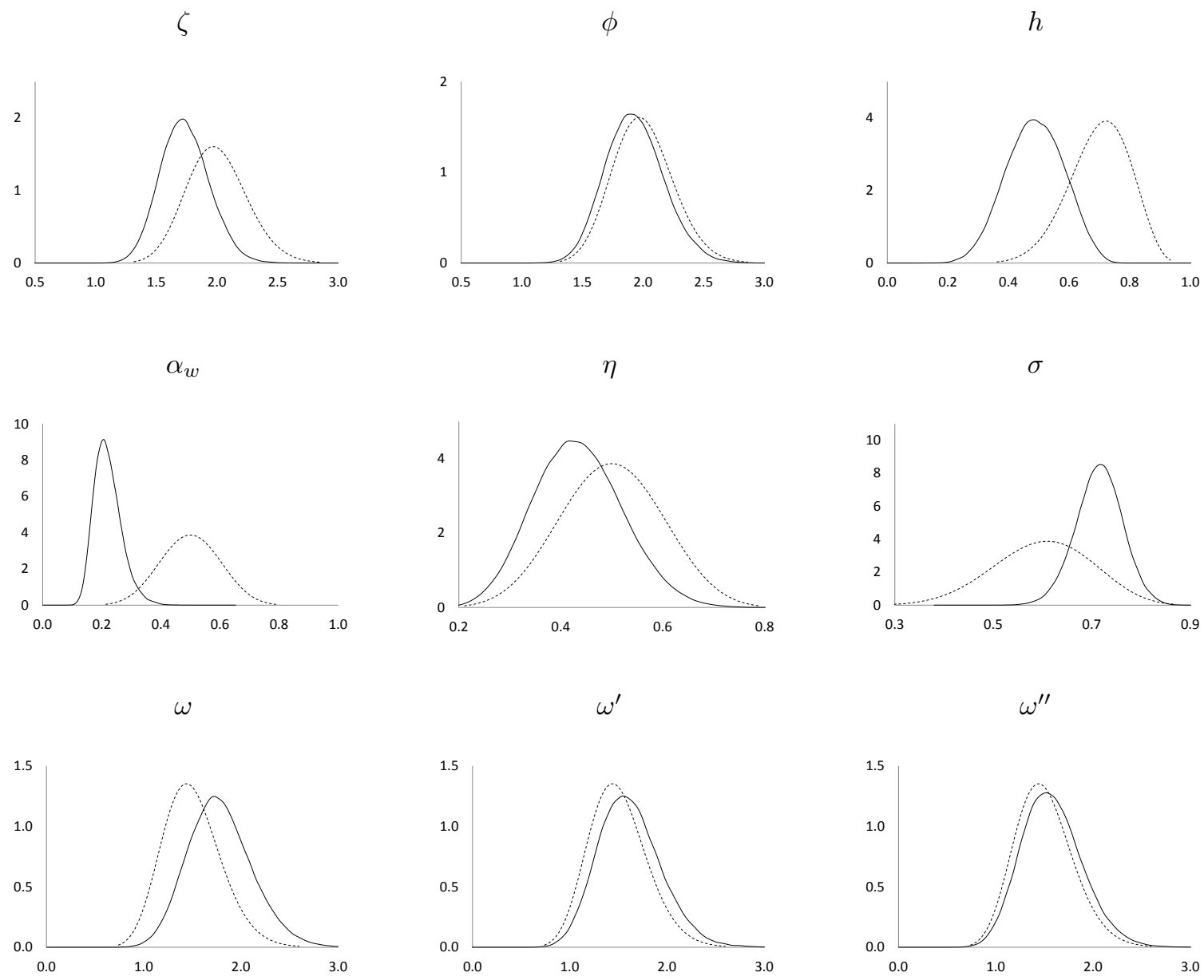

$\sigma_{z}$
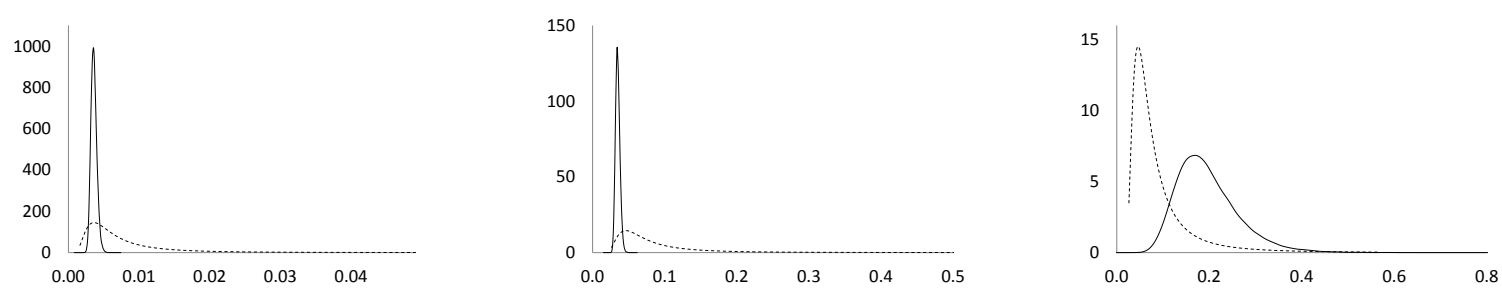

$\sigma_{g}$

$\sigma_{\beta}$

$\sigma_{v}$
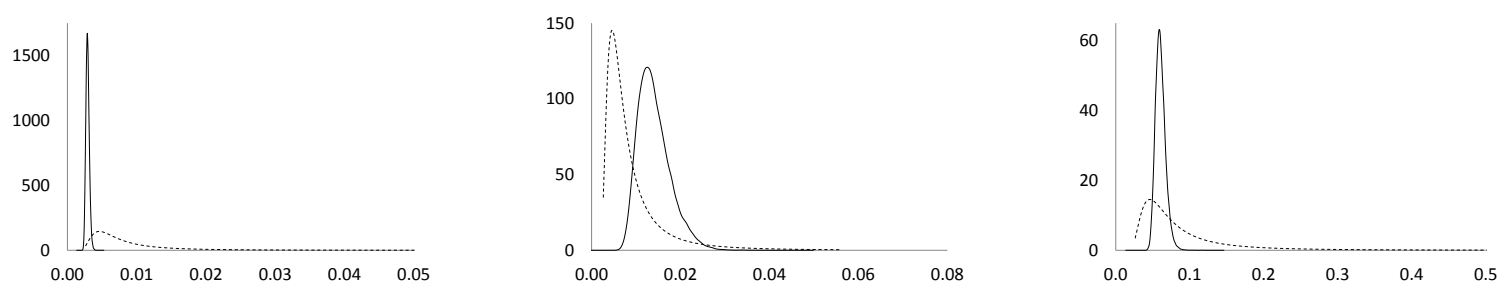
$\sigma_{y}$

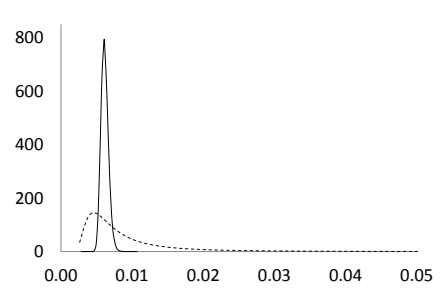

$\rho_{\eta}$

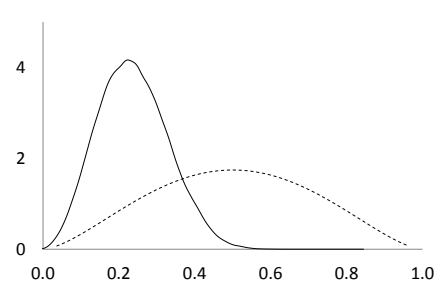

$\rho_{v}$

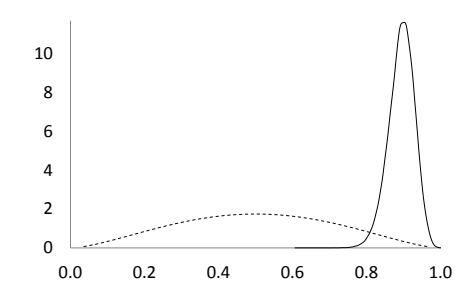

$\rho_{z}$

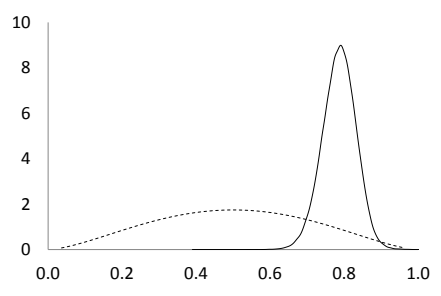

$\rho_{g}$

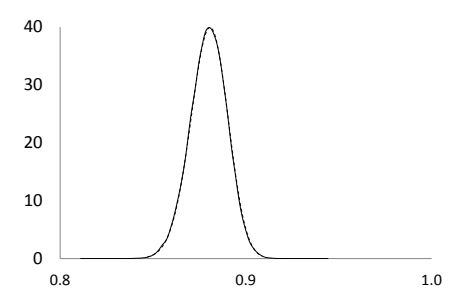

$\rho_{y}$

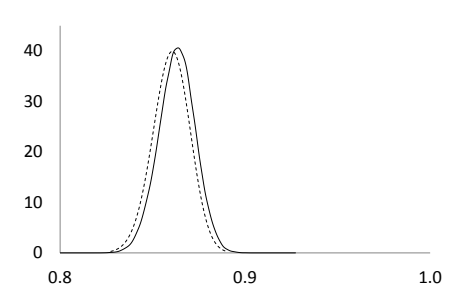

$\rho_{\varrho}$

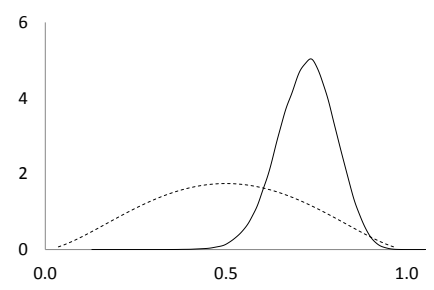

$\rho_{\beta}$

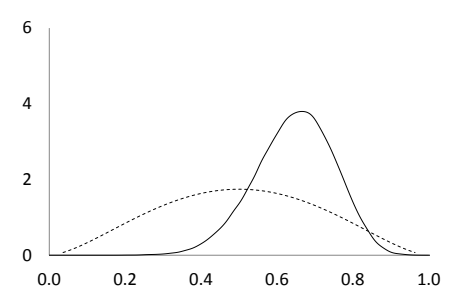

Note: Dashed line - prior distribution, solid line - posterior distribution 